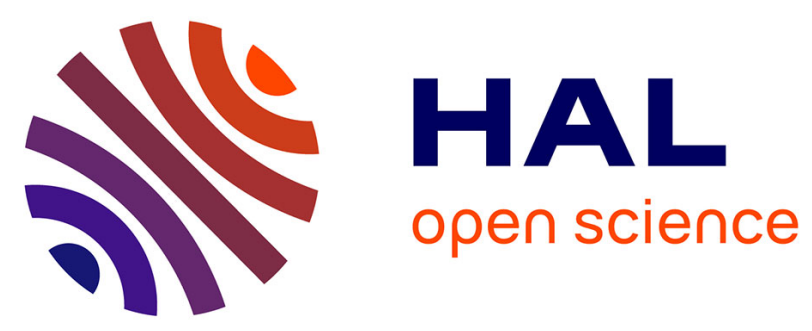

\title{
L'atelier de la Butte
}

Eric Bertrand, Armand Desbat, Sandrine Elaigne, Anne Schmitt

\section{To cite this version:}

Eric Bertrand, Armand Desbat, Sandrine Elaigne, Anne Schmitt. L'atelier de la Butte. Gallia Archéologie de la France antique, 1997, Les productions des ateliers de potiers antiques de Lyon (2e partie) : les ateliers du Ier s. après J.-C., 54, pp.5-43. 10.3406/galia.1997.3233 . halshs-01928632

\section{HAL Id: halshs-01928632 \\ https://shs.hal.science/halshs-01928632}

Submitted on 29 Jan 2020

HAL is a multi-disciplinary open access archive for the deposit and dissemination of scientific research documents, whether they are published or not. The documents may come from teaching and research institutions in France or abroad, or from public or private research centers.
L'archive ouverte pluridisciplinaire HAL, est destinée au dépôt et à la diffusion de documents scientifiques de niveau recherche, publiés ou non, émanant des établissements d'enseignement et de recherche français ou étrangers, des laboratoires publics ou privés.

\section{(a)(1) $\$$}

Distributed under a Creative Commons Attribution - NonCommercial - NoDerivatives 44.0 


\title{
L'ATELIER DE LA BUTTE
}

\author{
Eric Bertrand, Sandrine Elaigne, Armand Desbat et Anne Schmitt
}

\begin{abstract}
Résumé. Situé sur la vive gauche de la Sầne, en amomt de la Muette, sur la plare de la Butte, cet atelier a été découvert en 1965. Dans le même secteur avaient élé réalisées au XIX's. plusieners découvertes qui attestaiemt une production de lampes à huile. Les quelques vestiges recueillis à l'occasion des tratraux recents confirment une production de lampes mais anssi de valses à parois fines, de mortiers at de bouchons d'amphores, au milieu du Irs. après J.-C. L'étude du matériel des sites de consommation permet de supposer une activité sur plus d'un siecle.
\end{abstract}

\begin{abstract}
Situated on the left bank of the river Saone, upstream of la Muette, in la Butte square, this zuorkshop zuas disconered in 1965. In the same area several disconeries in the $19^{\text {i }}$ century gave evidence of a production of lamps. The fea remains collected recently confirm that lamps, but also thin-walled potteries, mortarias, amphoras stoppers were produced in the middle of the l' century. The study of the material from other sites let suppose an aitivity which lasted over a century.
\end{abstract}

\section{IRCONSTANCES DES DÉCOUVERTES}

Les traces d'une activité artisanale céramique ont ¿été mises en évidence quai Saint-Vincent, sur la place de la Butte (devenue place du 175" RIA), en 196̆́, à l'occasion de la pose par le service des Eaux de la ville de I yon, d'une double canalisation, destinée à une traversée sous-fluviale de la Saône (fig. 2). Les tranchées de mise en place de ces conduites de forte section ont éventré les niveaux de la place et le quai lui-même sur une hauteur de plusieurs mètres, révélant des structures antiques et une accumulation de couches contenant des déchets de fabrication de céramique et de verrerie. Ces observations ont été effectuées par A. Grange à qui l'on doit également des croquis et des relevés qui constituent la seule documentation sur ces découvertes. Aucune structure d'atelier n'est clairement apparue, hormis, dans une des coupes de la tranchée, une paroi rubéfiée pouvant se rapporter à un four. La couche riche en rebuts de cuisson surmontait un alignement de cuviers en céramique, dont la destination nous échappe, mais qui appartenaient à une installation artisanale antérieure. Toutefois, la pré- sence de ces couches d'épandages, riches en céramiques à parois fines et en lampes à huilc présentant toutes les caractéristiques de ratés de cuisson, atteste la production de ces types de céramique dans ce secteur.

Ces découvertes sont à rapprocher de celles signalées par A. Comarmond (1855-1857) qui rapporte la mise au jour d'un lot de lampes à huile «quai de Serin, à Lyon, en 1842, dans la propriété de M. Morel, fondeur de cloches, en faisant les fondations d'un mur" (Comarmond, 1855-1857, p. 92, n" 542). Il associc ces trouvailles à des découvertes plus anciennes (entre 1832 et 1834) faites au même emplacement : "Déjà dans cet endroit, on a fait de nombreuses découvertes, surtout en sujets érotiques; on y a même découvert les ruines d'un four de potier ainsi que des vases de formes variées, des outils s'appliquant à la céramique". Il précise également que «beaucoup d'objets qui provenaient de cet atelier étaient en terre blanche" et ajoute (ibid., p. 97, n"569) que l'atelier appartenait au potier Strobilius « attendu que ce seul nom figure sur les objets céramiques trouvés près du four dont nous avons parlé au n"542". Comarmond ćvoque encore "au lieu-dit de la Butte, en 1840, la récupération dans les ruines d'un four de potier, 


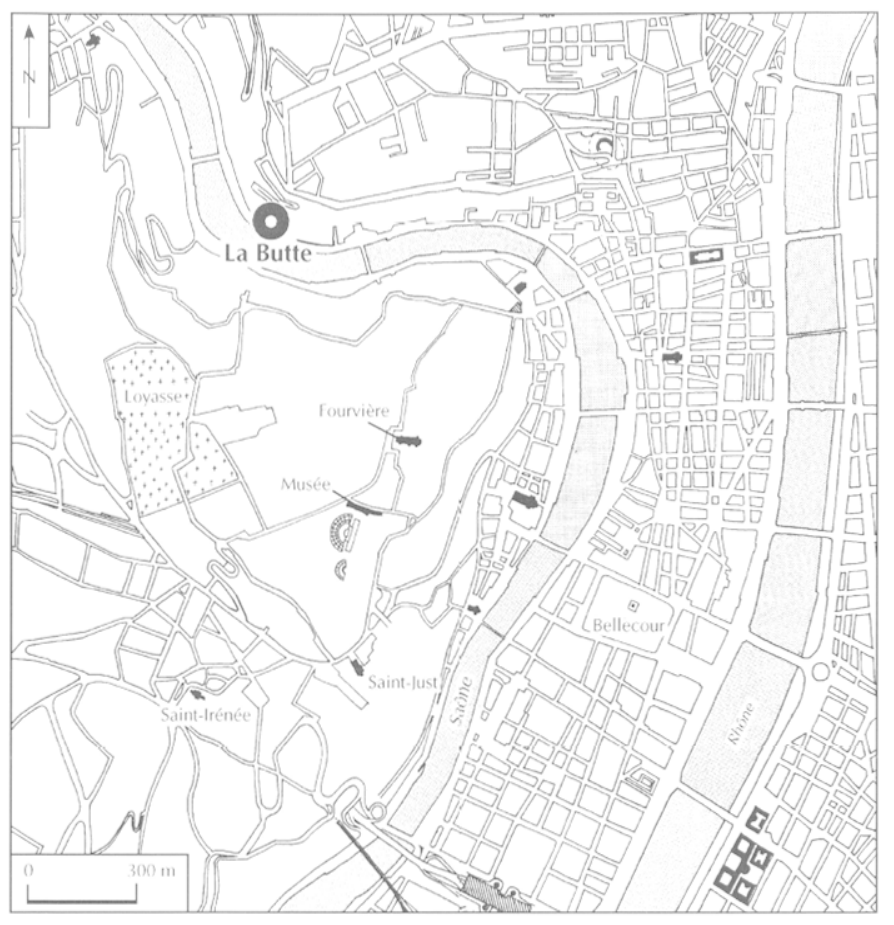

Fig. 2. Plan de localisation de lantelier de la Bulte.

de pièces d'ompilement on céramique "formant une partic plus ou moins complète du matériel de l'établissement " (Comarmond, 1855-1857, p. 112, n"644).

A. Stevert (1895, p. 282 et 289$)$ reprend A. Comarmond en ajoutant des précisions : "À tyon, il |Strobilius| avait une officine en pleine activité qui cetait située sur l'emplacement du quai de Serin, n"9, actuellement dépendant de l'usine (rillet. On y fabriquait des vases, des lampes [...]. Beaucoup d'objets qui en provenaient étaient de terre blanche" (Stevert, 1895, p. 282 (c) 329$)$ !.

I a mention de Comarmond et plus encore le résumé qu'en donne Steyert laissent croire à l'existence de deux lieux de décourerte (I asfargues, 1973, p. 527), un «au Nord du fort Saint-Jean" (Steyert) el l'autre place de la Butle.

lin effet, comarmond localise la propriété de M. Morel quai de Serin, or cette mention est crroné

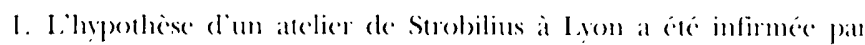
C. Jullian (1920)-1926, V. p. 38.1) qui soutenait que ce poticr cotit italien puisque certe signature est bien commue sur kes a lampes de firme " produites dans lat region de Modene. Fin ceffet, il parait plus probable (que latelier lyomais at produit des copies de lampes italiepues portant le " cachet" des originaux. puisque ledit Gécléon Morel est installé en fait "quai Sainte-Marie-des-Chânes, monté de la Butte ", d'après l'indicateur des professions de I yon de 1834. I aes différentes découvertes semblent bien concerner un seul et même atelier localisé place de la Butte.

liensemble des découvertes, modernes et plus anciennes, situe clairement la \%one d'activité de l'atelier en aval du Font Saint-Jean, entre la place de la Butte et la Manutention.

\section{I.ES PRODUCTIONS}

\section{CARACTÉRISTIQUES TECHNIQUES}

Pour la production des parois fines et des lampes, largile employée est très calcaire (taux supérieur à $8 \%$ ) et les engobes sont parfois grésés (c'est-à-dire imperméables et d'aspect plus ou moins brillant selon les conditions de préparation ou de conservation) ou non (poreux et mat) selon le degré de réussite de la cuisson. I a couleur de la pâte varie généralement du blanc au verdature et celle de l'engobe, par analogic aux parois fines, est généralement dans les tons bruns ou orangés (très rarement rouges).

Dans la série étudiée, les lampes ne présentent qu'exceptionnellement un revêtement brillant puisqu'il s'agit de ratés de cuisson, qui ont, pour une bonne part, une pâte verdâtre à engobe fondu, voire déformée par une cuisson à trop haute température el pour une autre part une pâte très pulvérulente où l'engobe a disparu. Mais il est difficile de discemer la cause de ce demier aspect car les conditions d'enfouissement aussi bien qu'une cuisson inacheréc peusent la justifier. lin outre, prespue toutes portent des pustules de surmoulage au plâtre.

\section{LES CÉRAMIQUES À PAROIS FINES}

Ies découvertes anciennes ne font que mentionner l'existence, place de la Butce, d'une production de céramiques de formes variées; alucun tesson de parois fines qui aurait pu être recucilli à cette époque ne nous est parvenu. Sans doute l'attention des historiens était-elle uniquement retenue par les lampes. Le matériel collecté place de la Butte provient donc essentiellement des tran- 
chées ouvertes sur la place en 196.5. Il constitue um ensemble modeste : 629 tessons réunis en petits lots, sans provenance stratigraphique suffisamment précise. Peu abondant, le matériel est aussi très fragmentaire.

\section{LES FORMES}

Du point de vue typologique, on pouvat attendre beaucoup d'un ramassage de tessons effectué sur le site même de l'atelier. Malheureusement, la fragmentation du matériel rend certaines leveres difficilement interprétables parmi un ensemble modeste de 84 vases (fig. 3). Au sein des productions de l'atelier de la Butte, la typologie des bols est la mieux connue, chaque type étant bien défini et sa production constante en qualité el pré- cision. Les bols à lère en biseau, légèrement carénés, sont faiblement représentés (pl. 1, n” 1 à 3). Parmi les bols hémisphériques, les bols à lève en bandeau lisse sont les plus courants (pl. 1, n" 4 à 20), devant les bols à lève en bandeau mouluré (pl. 1, n" 21 à 30). Les bols carénés à lèvre en bandeau brisé, plus tardifs, sont moins abondants (pl. 2, n" 1 à j).

Les pots ovoïdes forment un ensemble aussi important que les bols. I.es lèves, réalisées sur une base commune évasée, présentent de multiples variantes. I a recherche de profils complets sera indispensable au classement de ces formes fermées (pl. 2, n’ 27 à 31 ; pl. 3, n" 1 à 26 ; pl. 4, n" 1 à 24$)$.

Rarement répertoriéc, la forme du gobelet ovoïde (pl. 2, n² 24 à 26) peut être plus précisément décrite : la

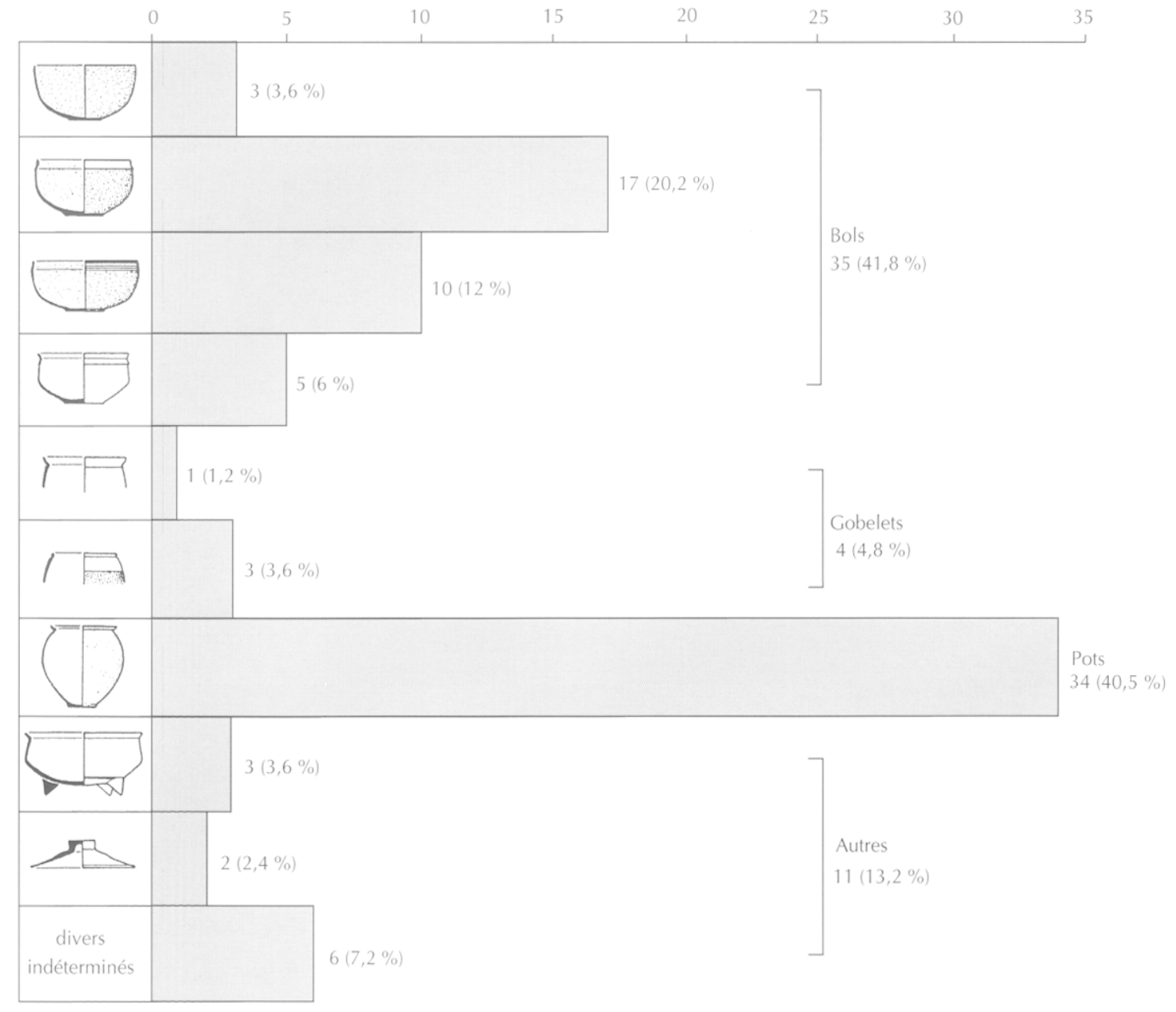

Fig. 3. Histogramme des fréquences absolues et relatives des formes. 

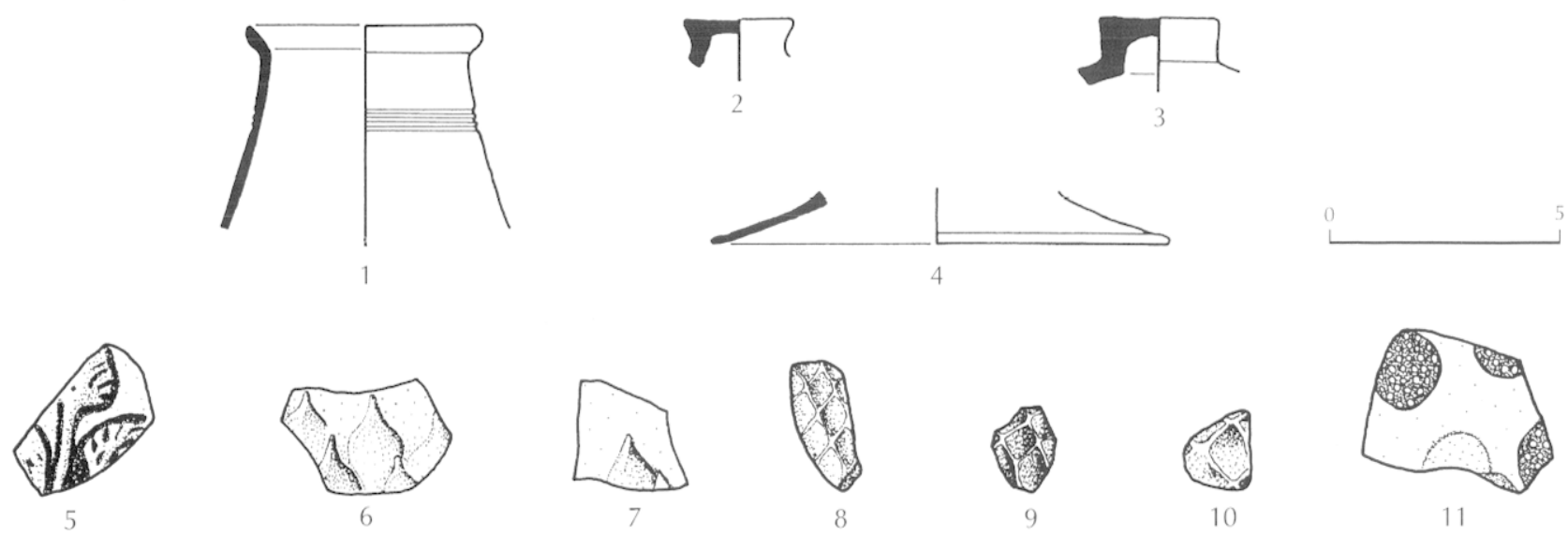

11
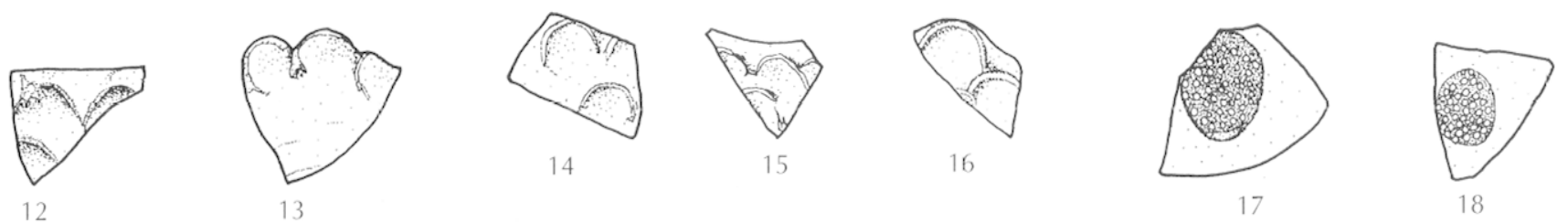

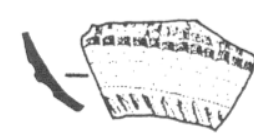

19

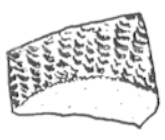

25

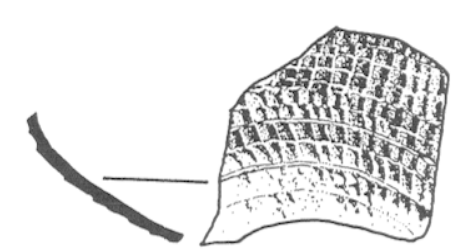

20

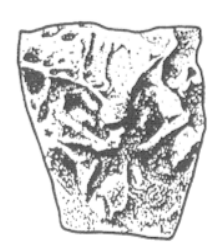

21

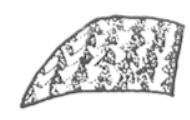

27

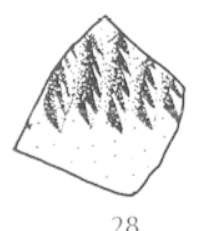

28

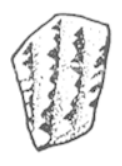

29

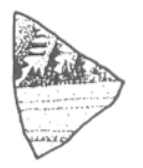

23

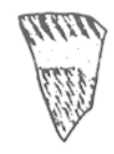

30

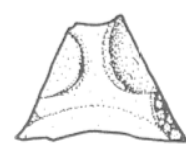

24

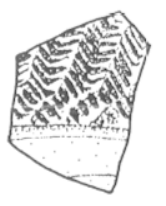

31

Fig. 4. Céramiques à parois fines de l'atelier de la Butte.

lèvre en micro-bourrelet, soulignée par un sillon, couronne un registre lisse qui l'isole de la panse décoréc (sablage, guillochis). Ia découverte d'une imitation de gobelet républicain à lèvre concave est un fait nouveau (pl. 2, n" 23). D'autres formes rares demeurent difficilement identifiables à partir du seul matériel de l'atelier (fig. 4, n" 1; pl. 2, n" 21 et 22). I es coupes tripodes sont généralement hémisphériques et munies d'une lère éversée (pl. 4, n" 25 à 28), elles illustrent la diversité de la production de l'atelier.

\section{LES DÉCORS}

L'analyse de l'ensemble des tessons, classés par décors, révèle quelques informations (fig. 5). Ie décor sablé est le plus ancien de l'atelier, il recouvre systématiquement les bols à levve en biseau qui ne recevront jamais de décoration à la barbotine. Ie sablage a été appliqué à la plupart des formes à l'exception des bols à lèvre en bandeau brisé et des couvercles. Si l'on s'intéresse de plus près à la face interne des tessons, on constate que $77,4 \%$ des tessons sablés ont une surface 


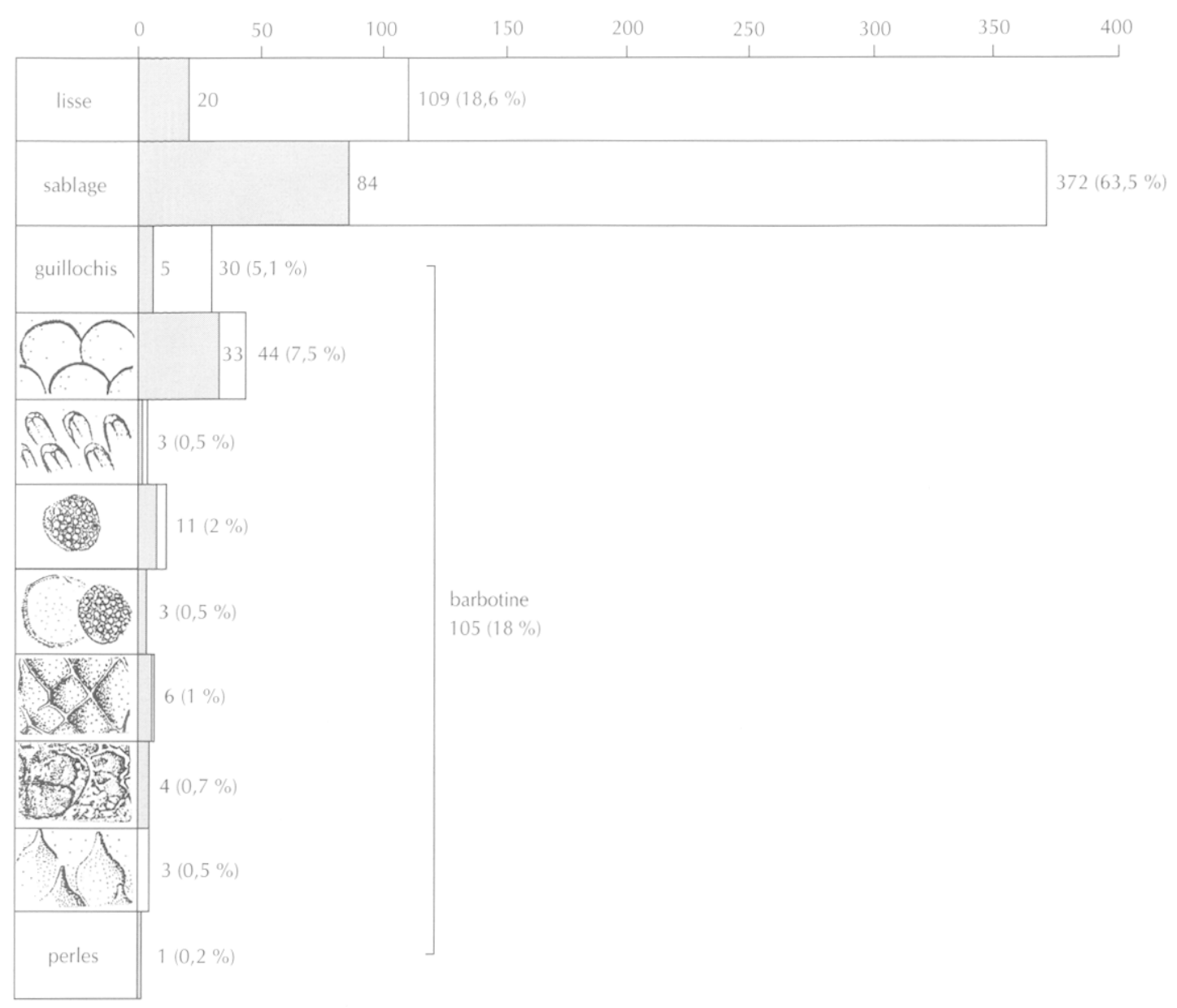

Fig. 5. Histogramme des fréquences absolues et relatives des tessons rangés par types de décors. lin tramé, le pourcentage des tessons dont la surface interme est sablée.

interne lisse. Il apparaît donc qu'une grande partie de ces tessons provient de formes fermées (pots ovoïdes) dont la paroi interne est moins systématiquement sablée que celle des formes ouvertes (bols), et dont la plus grande taille a généré plus de tessons. La même observation peut être faite pour les tessons lisses ou à décoration guillochéc (moins fréquentes sur les formes ouvertes).

I.es décors en relief, réalisés à la barbotine, sont bien moins abondants (12,8\% des tessons). Dans cette catégorie, les tessons portant des écailles sont les plus nombreux ; ce décor est courant sur les bols ( $75 \%$ des tessons à écailles sont sablés sur leur face interne) et se retrourc plus rarement sur les formes fermées (pl. 3, n*23). Bien souvent, la taille réduite des tessons ne permet malheureusement pas leur attribution à une forme précise.

\section{Chronologie}

Le matériel récolté sur le site de l'atelier n'illustre malheureusement qu'une partie de la typologie de la céramique à parois fines de la Butte. D'autres formes et d'autres décors ont été recensés par K. Greene sur le site d'Usk en Grande-Bretagne et dans les musées européens (Greene, 1979, lig. 8). La typologic qu'il propose est bien plus complète que celle que nous pourrions dresser avec le seul matériel de l'atelier. L a céramique mise au jour sur les sites de consommation de la région lyonnaise, et notamment celui de la rue des Farges, confirme ce constat (Grataloup, 1984). I.es lacunes observées dans la représentation du matériel de l'atelier s'expliquent par les conditions de la découverte du site (scule une infime partie de ce que l'on considère être l'atelier a pu être 
entrevue), mais aussi statistiquement, de petits ensembles pouvant être dépourvus des formes les moins fréquentes.

Quelques tessons de céramique sigillée (Caule du Sud) ont été récupérés avec la paroi fine trouvée place de la Butte. Ils nous permettraient de situer notre ensemble après les années 40 après J.-C. : l'établissement d'un terminus ante quem, plus délicat, doit être replacé dans le dernier quart du $\mathrm{I}^{\mathrm{a}} \mathrm{s}$. Cette datation s'accorde avec les constatations faites sur les sites de consommation où les décors à la barbotine font leur apparition un peu avant le milieu du I" s., sous le règne de Claude.

L'activité de l'atelier s'est étendue sur une plus grande durée. Ies stratigraphies de la rue des Farges révèlent l'apparition de la céramique à parois fines de la Butte autour des années 20-30 après J.-C. I a forme du bol à lère en biseau fournit, parmi les domées existantes, le plus ancien témoignage de la production de l'atelier. $\grave{A}$ Saint-Romain-en-Gal, elle est la seule forme de parois fines à pâte calcaire présente dans l'horizon SRG; 3 (15/20-40 après J.-C..) (Desbat et al., 1994). Sa disparition, avant le dernier tiers du I" s., est relativement précoce.

I es bols à lère en bandeau, bandeau mouluré, ainsi que les pots ovö̈les ne semblent appanature que quelques années plus tard. Ces formes, les plus abondantes sur les sites de consommation, ont eu la durée de vie la plus longue. Ie bol a levre en bandeau brise, les gobelets ovoïdes, les compes mipodes el les couvereles n’apparaissent pas dans les stratigraphies de la region lyomnaise anant le deuxiome ticrs du I" s. apres J.-C.

Nous disposons de contextes assez rapprochés dans le temps pour estimer le début de la production de l'atelier; mais à partir de la lin du $I^{n}$ s., les horizons stratigraphiques se dilatent pour couvrir des séquences chronologiques plus vastes. Il apparât désormais clairement que les formes les plus courantes de l'atelier de la Butte sont bien présentes sur les sites de consommation lyonnais à la fin du I" s. el persistent au début du IF" s. (figg. 6). I a clatation de l'arrêt de la production de l'atelier - autour des années 68-70 apres J.-C. - avancée par K. Crecne reposait sur l'absence de córamique de la Butte sur les sites fla viens et plus taudifs du limes, à une époque oì la cité de Iyon comnaissait des troubles politiques (Greenc, 1979, p. 141-142). l absence de materiel lyonmais sur les sites rhénans pourait ne signifier que la fin de la diffusion massive de la paroi fine lyomnaise. Une éude plus exhatustive des contextes du II s. serait nécessaire pour cemer aree plus de précision l'arrêt de la production et son crolution.

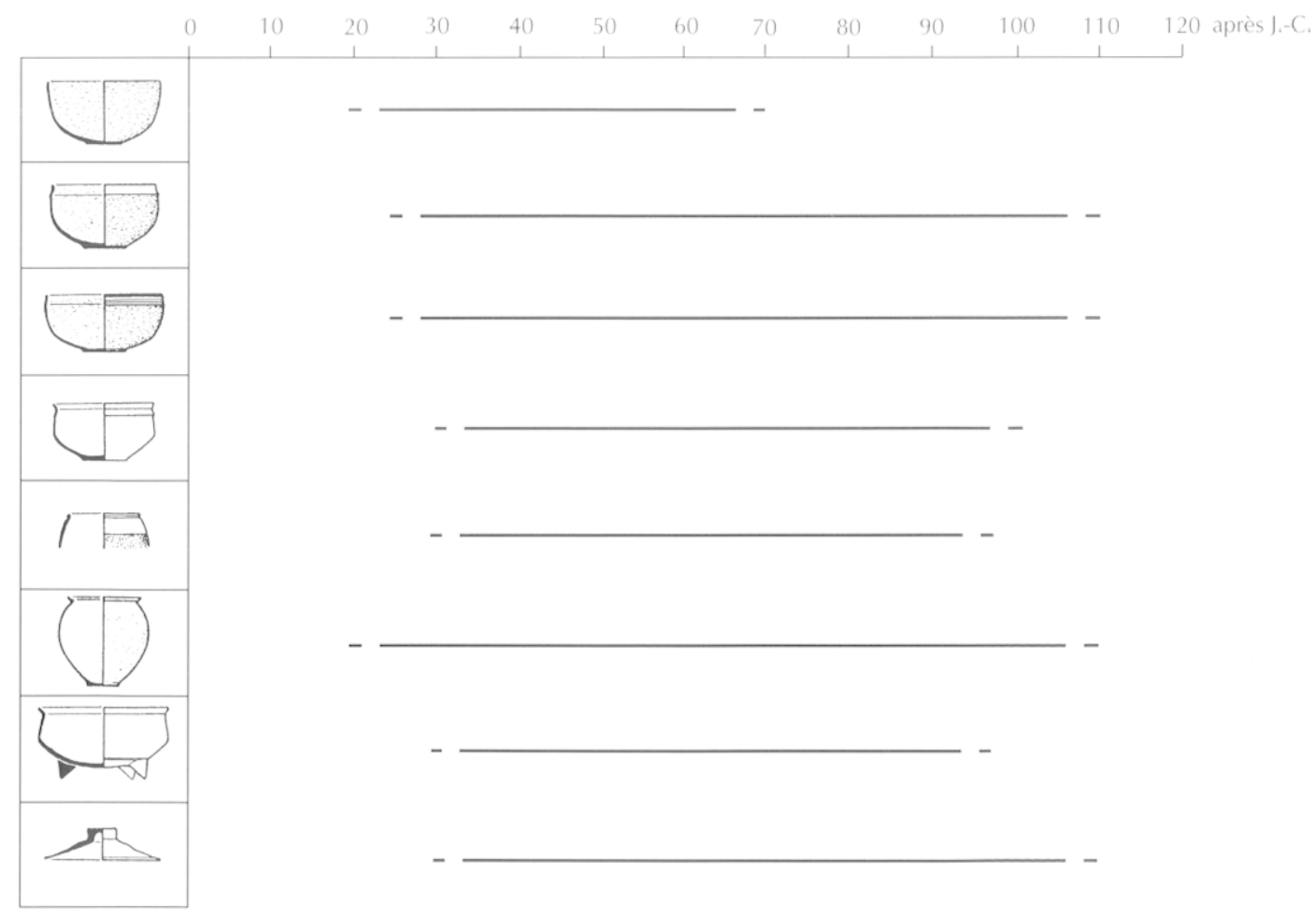

Fig. 6. Chromologie des principales formes de latelier de la Bulle. 


\section{DIFFUSION}

À l'exception d’une diffusion régionale limité vers le sud à la région viennoise, et probablement plus spora- dique vers l'ouest, les productions de l'atelier de la Butte ont ćcé principalement exportées vers le nord et vers l’est (fig. 7). Laxe Sâne-Rhin a conduit les productions lyonnaises vers le limes germanique et jusquen Grande-

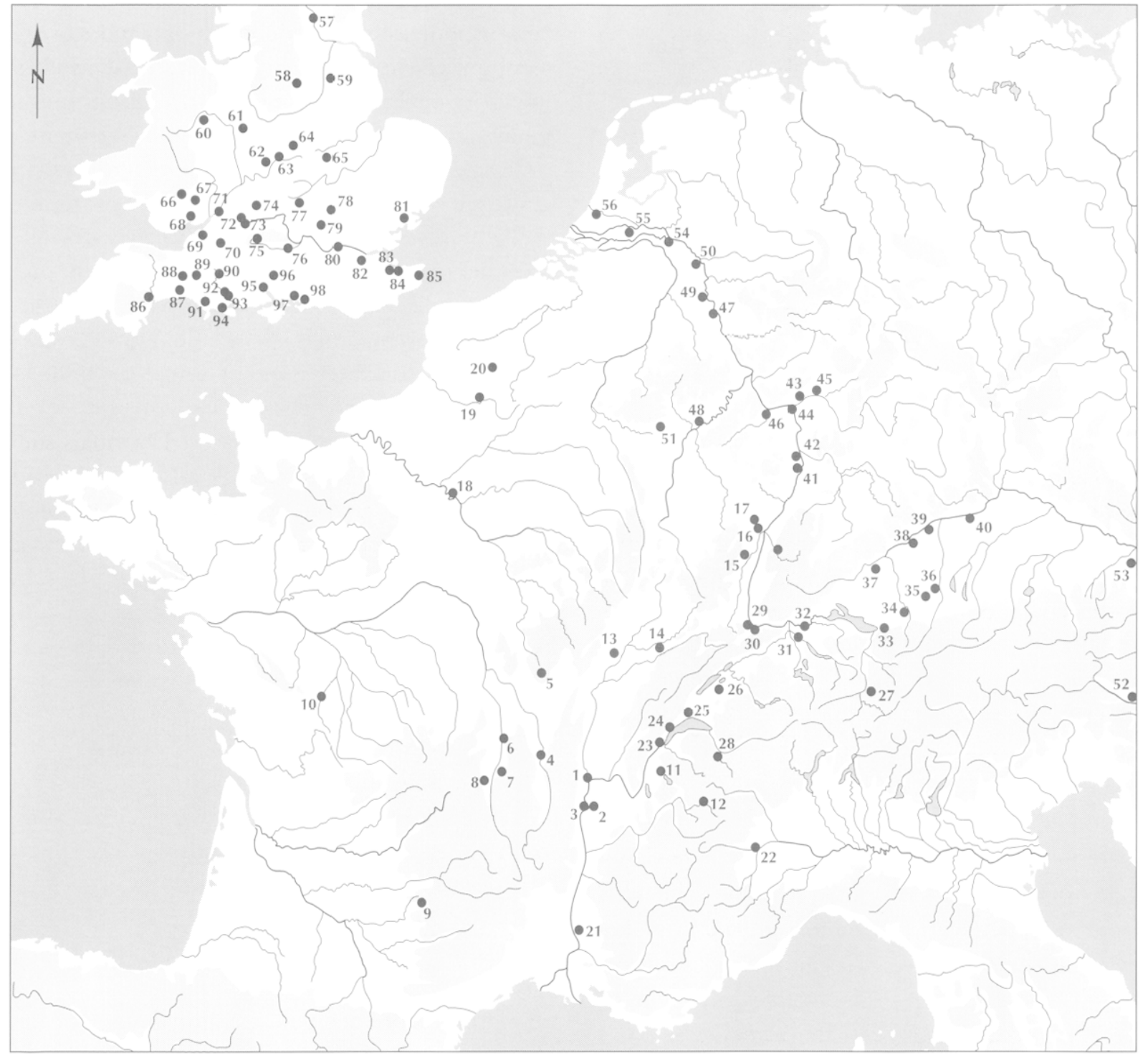

Fig. 7. Carte de répartition de la céramique à parois fines de latelier de la Butte.

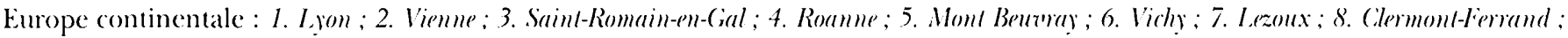

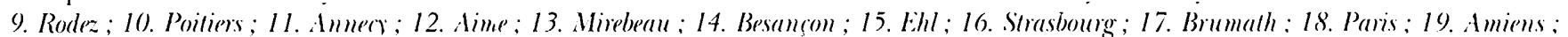

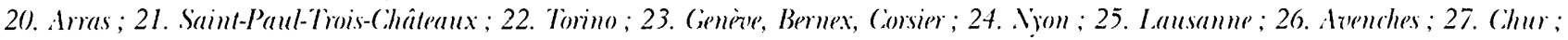
28. Martigny; ; 29. Bâle; 30. Augst ; 31. Vindonissa ; 32. Zurzach; 33. Bregenz; 34. Kemplen ; 35. Auerberg ; 36. L.orenzberg; 37. Risstissen ; 38. Aislingen ; 39. Burghöfe; 40. Obershimm; 41. Speyer; 42. Rheingönheim ; 43. Hofheim ; 44. Mainz; 45. Frankfurt ; 46. Bingen : t7. Köln : 48. Trier; 49. Neuss; 50. Xanten; 51. Arlon; 52. Magdalensberg ; 53. Carnuntum ; 54. Nijmegen; 55. Vechlen; 56. Valkenlurg; ;

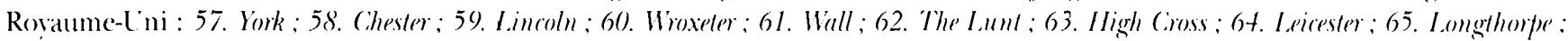

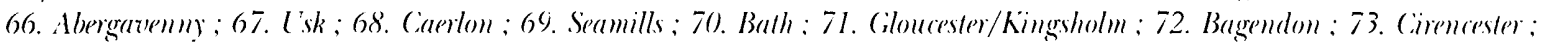

74. Salmonsbury ; 75. Wanborough; 76. Silchester; 77. Alchester : 78. Baldock; 79. Verulamium ; 80. Lomdom; 81. Coldhester ; 82. Lecles: 83. Faversham ; 84. Canterbury ; 85. Richborough ; 86. Exeter; 87. Haddon Hill; 88. Ham Hill ; 89. South Cadbury : 90. Hod Hill :

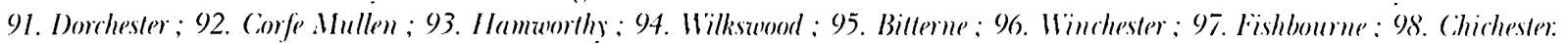


Bretagne où clles ont été recensées de façon exhaustive par K. Greene. En direction de l'est, le cours du Danube a permis d'atteindre Carnuntum et indirectement le Magdalensberg, tandis que le cours oriental du Rhin a desservi les villes du nord de la Suisse. I es sites bordiers du lac Ĺcman et de la Suisse méridionale ont pu être approvisionnés par le Rhône. I es établissements rhénans et de la Suisse jusqu'au cours amont du Danube apparaissent comme les débouchés principaux à l'exportation de l'atelier lyonnais.

E. B.

\section{LES LAMPES À HUILE}

\section{Présentation du matériel}

Deux lots se trouvant au Musée de la Civilisation galloromaine ont été mis à notre disposition : les lampes qui proviennent des repérages et des ramassages sélectifs de A. Grange à l'occasion des travaux de 1965, et celles du fonds ancien du Musée répertoriées dans le cataloguc de A. Comarmond.

En dehors de ces quelques lampes, la production de l'atelier de la Butte est principalement représentée par du matériel de dépotoir, en dehors de tout contexte stratigraphique.

Cet atelicr est d'ores et déjà connu pour sa production de céramiques à parois fines, qui a permis de situer son activité des années 20-30 après J.-C. jusqu'au début du II" s. de notre ère ${ }^{2}$. Il prendrait le relais de celui de la Muette et développerait au même moment la production de lampes à huile et de parois fines en utilisant pour ces deux catégories les mêmes techniques et les mêmes matériaux. Néanmoins, il est nécessaire de relativiser ce point de vue puisque l'on ne connaît que partiellement certaines couches-dépotoirs de l'atelier de la Butte à l'heure actuelle, et il se peut que des productions plus anciennes (augustéennes ou tibériennes), ou plus récentes (du II s.) notamment d'imitations de lampes de firme ${ }^{3}$, soient présentes dans d'autres dépotoirs encore inconnus du fait du hasard des découvertes.

2. Cette fourchette chronologique assez large a cić revue et préciséce par confrontation avec un contexte d'habitat (Elaigne, 1993).

3. On a signalé p. 6 la présence de la signature SIRROBII I.

\section{ÉTUDE DU MATÉRIEL}

Très fragmentaire, le lot prélevé par A. Grange comprend au total 500 fragments parmi lesquels on a pu identifier 185 individus dont 72 seulement ont pu être classés typologiquement.

Plus de la moitié des fragments comporte des caractéristiques de rebuts de cuisson : $34,2 \%$ des individus ont une pâte verdâtre surcuite et un engobe fondu et les pâtes pulvérulentes résultant d'une cuisson inachevée sont représentées par $32,9 \%$ des individus, ce qui confirme qu'il s'agit d'un dépotoir de fabrication.

Neuf des fragments de fonds prélevés possèdent une marque, ce qui pourrait indiquer soit une pratique courante au scin de l'atelier, soit une sélection effectuće au ramassage. Néanmoins l'échantillon reste représentatif de la production à un moment donné (celui de la constitution de ce dépotoir) et significatif du point de vue typologique et iconographique.

l.es exemplaires du fonds ancien répertoriés par A. Comarmond qui ont pu ĉtre observés sont aussi catalogués en vue de constituer des références, avec la mention " (O)M"; les indications concernant la description des pâtes et des engobes sont empruntées à A. Comarmond en raison de la ternissure des engobes.

Cortains de ces exemplaires ont l'intérêt d'avoir été comparés aux lampes de Vindonissa par S. Loeschcke en 1919 (en particulicr les exemplaires Butte 14 et 19 pour ceux qui nous intéressent). C'est en les observant que S. Loeschcke put constituer un groupe de provenance lyonnaise (groupe $\mathrm{C}$ ) pour certaines des lampes trouvées à Vindonissa (I.oeschcke, 1919, p. 252-254).

\section{TYPOLOGIE (fig. 8 à 12)}

En raison de la complexité morphologique de ce type de récipient, nous avons pris le parti de définir les tvpes selon divers critères : le caractère discriminant de chaque type est le bec et ses variantes ont été déterminées par des caractères annexes (profil du bec, aspect des volutes en raccord bec/bandeau). En outre, nous présentons les autres caractéristiques (anse, fond) susceptibles d'être des critères d'identification. L'ensemble de ces informations figure dans le tableau récapitulatif des types «Butte" (fig. 8 à 11$)^{4}$.

4. Les chiffres romains se rapportent au type et les chiffres arabes à l'exemplaire catalogué. 


\begin{tabular}{|c|c|c|c|c|}
\hline $\begin{array}{l}\text { TYPE } \\
\text { BUTTE }\end{array}$ & $\begin{array}{l}\text { RÉFÉRENCES } \\
\text { TYPOLOGIQUES }\end{array}$ & DESCRIPTION & FIGURES & $\mathbf{N}^{\circ}$ \\
\hline 1 & $\begin{array}{l}\text { Loeschcke IA } \\
\text { Muette III }\end{array}$ & $\begin{array}{l}\text { Bec triangulaire dont le rapport } \\
\text { longueur/largeur est défini par Loeschcke } \\
\text { (plus long que large), à volutes et boutons } \\
\text { simples. }\end{array}$ & & \\
\hline IA & $\begin{array}{l}\text { Bandeau } \\
\text { Loeschcke I }\end{array}$ & Bandeau à sillons en bordure. & & 1 \\
\hline IB & & $\begin{array}{l}\text { Bandeau à bord droit et décor d'oves } \\
\text { tournés vers l'intérieur. }\end{array}$ & & 2 \\
\hline IC & $\begin{array}{l}\text { Bandeau } \\
\text { Loeschcke VIIA }\end{array}$ & $\begin{array}{l}\text { Bandeau à bord oblique décoré de deux } \\
\text { sillons. }\end{array}$ & & 3 \\
\hline II & Loeschcke IB & $\begin{array}{l}\text { Bec triangulaire dont le rapport } \\
\text { longueur/largeur est défini par Loeschcke } \\
\text { (raccourci) à volutes et boutons simples. }\end{array}$ & & \\
\hline IIA & $\begin{array}{l}\text { Bandeau } \\
\text { Loeschcke I }\end{array}$ & Bandeau à sillons en bordure. & & 4 \\
\hline IIB & & $\begin{array}{l}\text { Bandeau à bord droit. Fond à pied } \\
\text { annulaire. }\end{array}$ & & \\
\hline IIB1 & $\begin{array}{l}\text { Bandeau } \\
\text { Loeschcke IVb }\end{array}$ & $\begin{array}{l}\text { Bandeau décoré d'un sillon. Anse-boudin } \\
\text { (à section ronde) ajoutée après moulage. }\end{array}$ & & 5 \\
\hline IIB2 & $\begin{array}{l}\text { Bandeau } \\
\text { Loeschcke IIIA }\end{array}$ & $\begin{array}{l}\text { Bandeau à bord droit décoré de trois } \\
\text { sillons, les deux derniers éloignés du } \\
\text { premier. }\end{array}$ & & $\begin{array}{l}6 \\
7\end{array}$ \\
\hline III & Loeschcke IC & $\begin{array}{l}\text { Bec triangulaire dont le rapport } \\
\text { longueur/largeur est défini par Loeschcke } \\
\text { (plus large que long), à volutes et boutons } \\
\text { simples. }\end{array}$ & & \\
\hline
\end{tabular}

Fig. 8. Typologie des lampes à huile de l'atelier de la Butte. 


\begin{tabular}{|c|c|c|c|c|}
\hline $\begin{array}{l}\text { TYPE } \\
\text { BUTTE }\end{array}$ & $\begin{array}{l}\text { RÉFÉRENCES } \\
\text { TYPOLOGIQUES }\end{array}$ & DESCRIPTION & FIGURES & $\mathrm{N}^{\circ}$ \\
\hline IIIA & & Bandeau à bord droit. & & \\
\hline IIIA1 & $\begin{array}{l}\text { Bandeau } \\
\text { Loeschcke IIIb } \\
\text { ou IVa }\end{array}$ & Bord droit décoré de deux sillons. & & 8 \\
\hline IIIA2 & $\begin{array}{l}\text { Bandeau } \\
\text { Loeschcke IIla }\end{array}$ & $\begin{array}{l}\text { Bord droit décoré de trois sillons, les deux } \\
\text { derniers éloignés du premier. }\end{array}$ & & $\begin{array}{c}9 \\
10\end{array}$ \\
\hline IV & $\begin{array}{l}\text { Loeschcke III } \\
\text { Muette II }\end{array}$ & $\begin{array}{l}\text { Anse-réflecteur moulée avec le corps de } \\
\text { la lampe et perforée. }\end{array}$ & & \\
\hline v & Loeschcke IV & Bec à extrémité ogivale et à volutes. & & \\
\hline VA & $\begin{array}{l}\text { Loeschcke IV } \\
\text { précoce }\end{array}$ & $\begin{array}{l}\text { Volutes convergentes vers l'extrémité } \\
\text { du bec. }\end{array}$ & & \\
\hline VA1 & $\begin{array}{l}\text { Bandeau } \\
\text { Loeschcke IIla }\end{array}$ & $\begin{array}{l}\text { Bandeau à bord droit décoré de trois sillons, } \\
\text { les deux derniers éloignés du premier. }\end{array}$ & & $\begin{array}{l}11 \\
12 \\
13\end{array}$ \\
\hline VA2 & $\begin{array}{l}\text { Bandeau } \\
\text { Loeschcke VIIb }\end{array}$ & Bandeau à bord oblique décoré d'un sillon. & & 14 \\
\hline VB & $\begin{array}{l}\text { Loeschcke IV } \\
\text { canonique }\end{array}$ & Volutes raccourcies et parallèles. & & \\
\hline VB1 & $\begin{array}{l}\text { Bandeau } \\
\text { Loeschcke lla }\end{array}$ & $\begin{array}{l}\text { Bandeau à bord droit décoré de trois sillons. } \\
\text { Fond à pied simple. }\end{array}$ & & $\begin{array}{l}15 \\
16\end{array}$ \\
\hline
\end{tabular}

Fig. 9. Typologie des lampes à huile de lintelier de la Bulte. 


\begin{tabular}{|c|c|c|c|c|}
\hline $\begin{array}{l}\text { TYPE } \\
\text { BUTTE }\end{array}$ & $\begin{array}{l}\text { RÉFÉRENCES } \\
\text { TYPOLOGIQUES }\end{array}$ & DESCRIPTION & FIGURES & $\mathrm{N}^{\circ}$ \\
\hline VB2 & $\begin{array}{l}\text { Bandeau } \\
\text { Loeschcke IIla }\end{array}$ & $\begin{array}{l}\text { Bandeau à bord droit, décoré de trois sillons. } \\
\text { Les deux derniers éloignés du premier. }\end{array}$ & & $\begin{array}{l}17 \\
18 \\
19\end{array}$ \\
\hline VB3 & $\begin{array}{l}\text { Bandeau } \\
\text { Loeschcke VIIb }\end{array}$ & Bandeau à bord oblique, décoré d'un sillon. & & 20 \\
\hline VB4 & $\begin{array}{l}\text { Bandeau } \\
\text { Loeschcke VIb } \\
\text { ou VIla }\end{array}$ & $\begin{array}{l}\text { Bandeau à bord oblique, décoré de deux } \\
\text { sillons. }\end{array}$ & & 21 \\
\hline VB5 & $\begin{array}{l}\text { Bandeau } \\
\text { Loeschcke VIIIb }\end{array}$ & $\begin{array}{l}\text { Bandeau à bord oblique, décoré de trois sillons. } \\
\text { Fond à pied simple. }\end{array}$ & & $\begin{array}{l}22 \\
23\end{array}$ \\
\hline VI & Loeschcke VIII & Bec à extrémité arrondie sans volutes. & & \\
\hline VIA & $\begin{array}{l}\text { Bec Loeschcke K } \\
\text { Bandeau } \\
\text { Loeschcke VIIIb }\end{array}$ & $\begin{array}{l}\text { Bec surligné par un méplat. } \\
\text { Bandeau à bord oblique, décoré d'un } \\
\text { bourrelet, d'un sillon et d'oves tournés } \\
\text { vers l'extérieur. }\end{array}$ & & $\begin{array}{l}24 \\
25 \\
26\end{array}$ \\
\hline VIB & Bec Loeschcke L2 & Bec semi-circulaire séparé du bandeau. & & \\
\hline VIB1 & $\begin{array}{l}\text { Bandeau } \\
\text { Loeschcke IIIa }\end{array}$ & $\begin{array}{l}\text { Bandeau à bord droit, décoré de trois sillons, } \\
\text { les deux derniers éloignés du premier. }\end{array}$ & & 27 \\
\hline VIB2 & & $\begin{array}{l}\text { Bandeau à bord oblique, décoré par un } \\
\text { méplat. }\end{array}$ & & $\begin{array}{c}28 \\
\text { à } \\
32\end{array}$ \\
\hline VIC & Bec Loeschcke H & Bec semi-circulaire rattaché au bandeau. & & \\
\hline VIC1 & $\begin{array}{l}\text { Bandeau } \\
\text { Loeschcke VIIb }\end{array}$ & Bandeau à bord oblique, décoré d'un sillon. & & 33 \\
\hline VIC2 & $\begin{array}{l}\text { Bandeau } \\
\text { Loeschcke VIb } \\
\text { ou VIla }\end{array}$ & Bandeau à bord oblique, décoré de deux sillons. & & 34 \\
\hline
\end{tabular}

Fig. 10. Typologie des lampes à huile de latelier de la Butte. 


\begin{tabular}{|c|c|c|c|c|}
\hline $\begin{array}{l}\text { TYPE } \\
\text { BUTTE }\end{array}$ & $\begin{array}{l}\text { RÉFÉRENCES } \\
\text { TYPOLOGIQUES }\end{array}$ & DESCRIPTION & FIGURES & $\mathrm{N}^{\circ}$ \\
\hline VII & $\begin{array}{l}\text { Deneauve VIB } \\
\text { Bandeau } \\
\text { Loeschcke IIIb } \\
\text { ou IVa }\end{array}$ & $\begin{array}{l}\text { Bec à extrémité arrondie, inclus dans le } \\
\text { bandeau. } \\
\text { Bandeau à bord droit, décoré de deux sillons. } \\
\text { Fond simple, sans pied. } \\
\text { Anse moulée avec le corps de la lampe et } \\
\text { perforée. }\end{array}$ & & $\begin{array}{l}67 \\
\text { à } \\
71\end{array}$ \\
\hline VIII & Loeschcke VI & $\begin{array}{l}\text { Bec à extrémité arrondie et boutons sans } \\
\text { volutes. } \\
\text { Bandeau à bord droit, décoré d'un sillon et } \\
\text { d'oves tournés vers l'extérieur. } \\
\text { Fond à pied simple. } \\
\text { Anse moulée et perforée. }\end{array}$ & & $\begin{array}{l}72 \\
73\end{array}$ \\
\hline IX & $\begin{array}{l}\text { Loeschcke IX A } \\
\text { Imitation de } \\
\text { lampe de firme }\end{array}$ & $\begin{array}{l}\text { Bec allongé à extrémité arrondie et canal fermé } \\
\text { sur le bourrelet du bandeau. } \\
\text { Bandeau à bord oblique et bourrelet décoré } \\
\text { d'ailerons latéraux lobés. }\end{array}$ & & $\begin{array}{l}74 \\
75\end{array}$ \\
\hline$x$ & $\begin{array}{l}\text { Loeschcke IX/X } \\
\text { Bandeau } \\
\text { Loeschcke IX }\end{array}$ & $\begin{array}{l}\text { Bec à extrémité arrondie et canal. } \\
\text { Bandeau à bord oblique à bossettes et } \\
\text { bourrelet. }\end{array}$ & & \\
\hline
\end{tabular}

Fig. 11. Typologie des lampes a huile de latelier de la Buate.

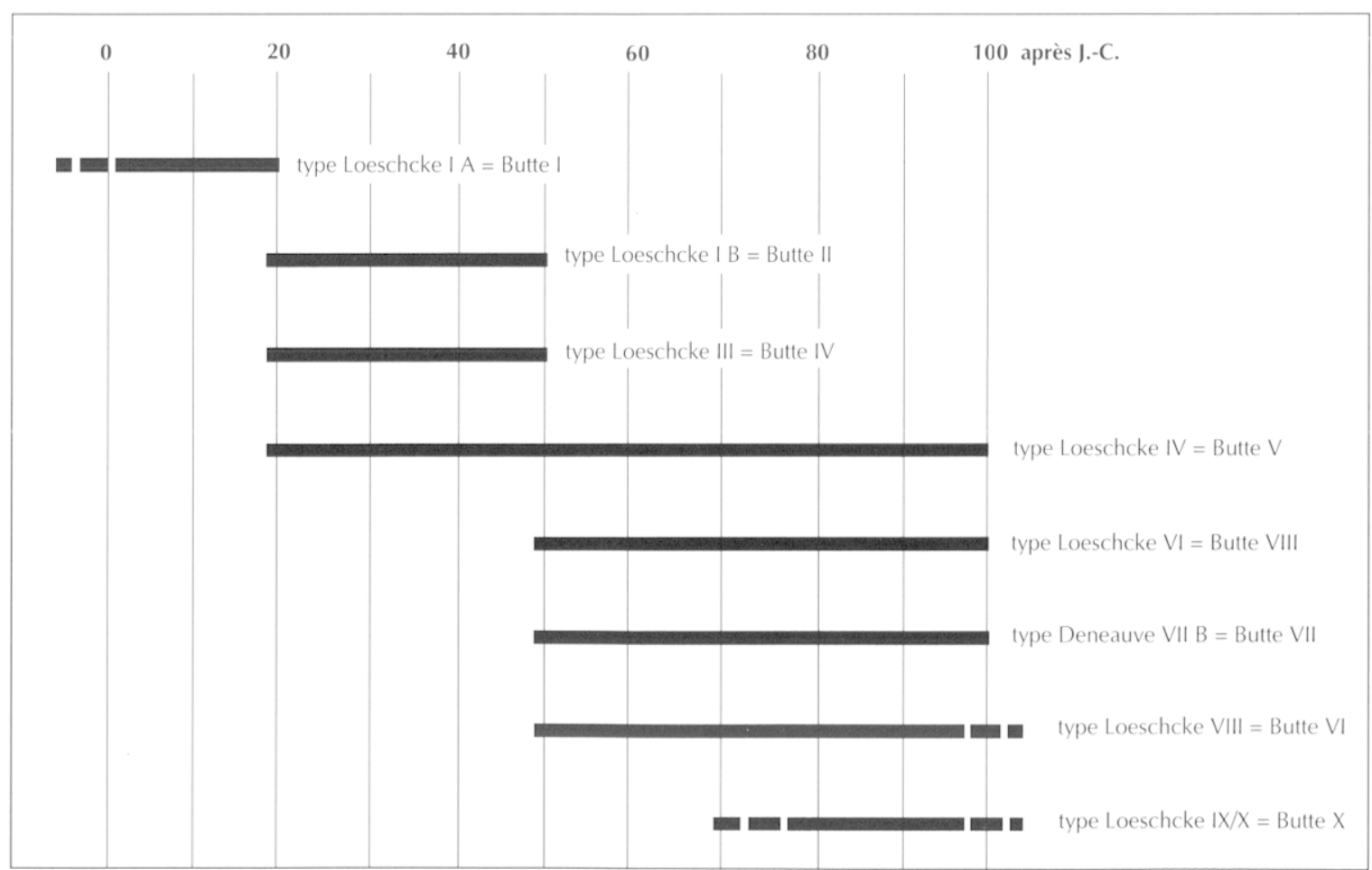

Fig. 12. Tablean chromologique des differemts types de lampes de l'atelier de la Bulle. 
Catalogue (pl. 5à 11)

Type I A (pl. 5)

Nol (BUT.65.149) : lampe fragmentaire en pâte beige, engobée en brun.

Diamètre : $8 \mathrm{~cm}$.

Trou d'évent circulaire.

Type I B (pl. 5)

N"2 (BUT.65.23) : fragment de bandeau en pâte beige, engobée en brun orangé.

Diamètre : $8 \mathrm{~cm}$.

Pustules de surmoulage au plâtre.

Parallèles : $c f$. Muette 7. Les oves sur bandeau sont fréquemment employés sur le type Muette III avec les oves tournés vers l'intéricur. C'est le cas de deux exemplaires datés de 30 à 15 avant J.-C. du site de la rue des Farges, et de trois exemplaires du contexte daté de 15 avant J-C. à 10 de notre ère de ce même site.

Type I C (pl. 5)

N"3 (BUT.65.15) : lampe fragmentaire en pâte blanche pulvérulente, engobée en brun.

Bec triangulaire dont les quatre boutons de volutes sont formés comme sur le type Butte $\mathrm{V}$.

Diamètre : $6,5 \mathrm{~cm}$.

Sans trou d'évent.

Médaillon : rosette à 8 pétales.

Parallèles : $c f$. Butte 20 et 21 sur les types Butte V (Loeschcke IV) et Butte 45. Ce décor est présent sur un exemplaire de type Butte VI de la seconde moitié du Irr $s$. du site de la rue des Farges; il est connu à Alba-la-Romaine sur un type Loeschcke $\mathrm{V}$ (Ayala, 1990, n" 46, fig. 15, p. 195) et à Vindonissa sur Loeschcke V et VIII (Locschcke, 1919, taf. I et II, n“318, 618 à 672).

Type II A (pl. 5)

No 4 (BUT.65.35) : lampe fragmentaire en pâte rose, engobée en rouge.

Trou d'évent circulaire.

Médaillon à décor non identifié (oiseau ?).
Type II B1 (pl. 5 et 10)

N" 5 (BUT.65.30) : lampe fragmentaire en pâte verdâtre à engobe fondu; surcuit.

Trou d'évent circulaire.

Longucur : $7,7 \mathrm{~cm}$; diamètre $: 5,5 \mathrm{~cm}$.

Fond à pied simple.

Médaillon lisse?

Type II B2 (pl. 5 et 10)

N” 6 (BUT.65.52) : lampe fragmentaire en pâte pulvérulente, engobće en brun orangé.

Longueur : $10,5 \mathrm{~cm}$; diamètre : $7,3 \mathrm{~cm}$.

Fond à pied annulaire.

Trou d'évent circulaire.

Pustules de surmoulage au plâtre.

Médaillon : Thrace brandissant la sica.

Parallèles : cette figure peut être représentée par trois poinçons similaires mais différents (dont un avec la tête de profil et un autre avec la sica au niveau du menton). Avec le même poinçon, on la trouve au Magdalensberg sur type Butte I (Muctte III/Loeschcke I A) daté du règne d'Auguste au début de celui de Tibère (Farka, 1977, taf. 73, n" 337, motif 91, p. 131), à Vindonissa sur type Loeschcke I (Loeschcke, 1919, taf. X, n" 135-136), en Italie sur type Butte II (Locschcke I B) daté du premier tiers du I" s. (Bailey, 1980, pl. 3, Q783, p. 54 et 138) et à Carthage sur Loeschcke I (Deneauve, 1969, pl. XXXVIII, n"317).

No7 (COM.548) : lampe complète; "argile blanche, engobe gris-jaune ".

Longueur : $11,1 \mathrm{~cm}$; diamètre $: 7,8 \mathrm{~cm}$.

Trou d'évent circulaire.

Fond à pied annulaire avec marque en creux : IS ?

Médaillon : scène de gladiature (Thrace et Samnite).

Parallèles : rf. Butte 81 ; on connaît une scène similaire au Magdalensberg dans un contexte daté d'Auguste/Tibère mais réalisée avec un poinçon différent pour le Samnite (Farka, 1977, taf. 37, n' 1012 , motif 83 , p. 129)

Type III Al (pl. 5)

No 8 (BUT.65.1) : lampe fragmentaire en pâte beige, 
engobée en brun.

Diamètre : $6 \mathrm{~cm}$.

Sans trou d'évent.

Fond à pied annulaire.

Type III A2 (pl. 5 et 6)

No9 (BUT.65.11) : lampe fragmentaire en pâte pulvérulente, engobéc en brun.

Trou d'évent remplacé par une pustule de surmoulage au plâtre.

Longueur : $9 \mathrm{~cm}$; diamère: $7 \mathrm{~cm}$

Fond à pied simple.

Anse non identifiable appliquéc après moulage.

Médaillon : Éros tenant un coquillage et s'appuyant sur un alabastron avec la main droite.

Parallèles : deux médaillons avec ce motif sont issus du contexte fin II'-début III"s. de la rue des Farges. Cette iconographie est très disséminéc géographiquement. On la retrouve à Trèves sur types Butte II (Iooschcke I B), Butte III (Iooschcke I C) et Butte $\mathrm{V}$ (I oeschcke IV) daté des règnes de Claude/ Néron aux Flaviens (Gocthert-Polascheck, 1985, taf. 23, n" 227 (retracé), motif 11, p. 95), à Hofheim, à Vindonissa sur I oeschcke I (Ioeschcke, 1919, taf. V, n" 22 à 24) et à Vidy sur types Butte II (Locschcke I B) et Butte V (I ooschcke IV) daté du deuxième quart du $I^{n}$ s. au II" s. (I ceibundgut, 1977, taf. 30, n“ 162 à 164, motif 87, p. 147), all Magdalensberg sur type Butte II (Locschcke I B) daté de l'époque tibéro-claudienne (Farka, 1977, taf. 28, n"418, motif 9, p. 108), à Carthage sur I oeschcke V (Deneauve, 1969, pl. I.X, n” 587 ct 588 retracés) et à Éphèse sur type Butte VI (loeschcke VIII) daté des Flaviens à Trajan (Bailey, 1988, pl. 101, Q3047, p. 376).

N"10 (BUT.65.21) : fragment de lampe en pâte verdâtre et engobe fondu; surcuit.

Bec fragmentaire; bandeau VII I).

Diamètre : $7 \mathrm{~cm}$.

Décor médaillon mal identilié : visage féminin tourné vers la gauche, appartenant vaisemblablement à une scène érotique.

Parallèles : un exemplaire daté de Tibère/Claude de la rue des Farges semble avoir été fabriqué avec le même poinçon et peut-être un autre exemplaire du même site daté de la seconde moitié du I" s. et surmoulé.

\section{Type IV}

Il faut noter la présence de deux fragments hors catalogue qui attestent la fabrication de ce type par l'atelier de la Butte, mêne si ce fut exceptionnel. Ceux-ci sont représentés par un fragment d'anseplastique de grand module en pâte beige pulvérulente engobéc en brun et par un fragment de cuve à départ d'anse-plastique en pâte blanche pulvérulente engobéc en orangé.

Type V Al (pl. 6)

N" 11 (C.OM.552) : lampe complète; "argile blanche et engobe rougeâtre".

Longucur : $9,4 \mathrm{~cm}$; diamètre : $6,6 \mathrm{~cm}$.

Trou d'event circulaire.

Fond a pied amnulaire.

Surmoulage ayant estompé les reliefs.

Médaillon : galère à proue en tête de cygne voguant vers la droite sur des flots stylisés.

Parallèles : décor répandu, notamment attesté à Tròves sur type Butte V (Ioeschcke IV) (GocthertPolascheck, 1985, taf. 58, n"487, motif 152, p. 244), à Vindonissa sur type Butte III (Ioeschcke I C.) (Icibundgut, 1977, taf. 36, motif 164, p. 161) et à Chypre sur type Butte V (I ocschcke IV) daté de 40 à 100 (Bailcy, 1988, Q2397, p. 45; Q2398, p. 303).

N"12 (C.)M.554) : lampe complète; "argile blanche, engobe rougcatre"

Trou d'évent en fente.

I.ongueur : $10 \mathrm{~cm}$; diamètre: $7,1 \mathrm{~cm}$.

Fond à pied simple avec marque en relief en forme de croix, situéc à l'opposé du bec près du sillon marquant le pied.

Marque sans parallèle.

Médaillon : cornes d'abondance symétriques.

Parallèles : motif très commun dans tout l'Empire mais qui peut être fabriqué avec plusieurs poinçons diférents. I e même poinçon est attesté à Chypre sur type Butte V (I oescheke IV) de la seconde moitié du I" s. (Bailey, 1988, Q2439, p. 88) et à 
Carthage sur ce même type (Dencaure, 1969, pl. XIVIII, " 454 ).

N"13 (COM.557) : lampe complète; "argile blanche, engobe orangé ".

I.ongueur : $9,8 \mathrm{~cm}$; diamòtre: $7,1 \mathrm{~cm}$.

Sans trou d'évent.

Fond à pied simple.

Relief émoussé dû au surmoulage.

Médaillon : cerf bondissant vers la droite.

Parallèles : motif très répandu, attesté à Vienne sur type Butte II (Ioeschcke I B) (Trial, 1988, pl. 6, décor 7), à Trèves sur types Butte II et Butte V (Iocschcke IV) (Goethert-Polascheck, 1985, taf. 38, n"' 194 ct 219; taf. 59, n" 461 et 518, motif 177 , p. 253), à Vindonissu el Augst sur types Butte II et Butte V (loeschcke, 1919, taf. XIII, n" 501 et I.eibundgut, 1977, taf. 48, motif 296 , p. $180 ; n^{\prime \prime} 293$ à 300 , p. $234 ; n^{\prime \prime} 467$, p. 250), à Neuss, à Xanten sur type Butte II, en Grande-Bretagne sur type Butte VI (Ioeschcke VIII) de 50) à 90 (Bailcy, 1988, pl. 1, Q1494, p. 70 et 157 ; pl. 64, Q2407, p. 70 ct 304), en Italie sur types Butte II, daté des deuxième et troisième quarts du $I^{\text {rr }}$ s., et Butte VI daté de $50 / 80$ (Bailey, 1980, pl. 37, Q1085, p. 228; pl. 56, Q1204, p. 75 et 297), à Carthage sur types Butte II, Butte V (retracé) et Iocschcke V (Deneauve, 1969, pl. XI, n" 353 ; pl. I.II, n" 503 ; pl. I.XIII, n" 624).

Type V A2 (pl. 6 ce 10)

N"14 (COM.605) : lampe fragmentaire ; "argile blanche, engobe brun ".

Longueur : $9,7 \mathrm{~cm}$; diamètre : $7 \mathrm{~cm}$.

Trou d'évent circulaire.

Pustules de surmoulage au plâtre.

Médaillon : crabe.

Parallèles : un exemplaire de la seconde moitié du I" s. du site de la rue des Farges sur type Butte V (loeschcke IV) porte cette figure. Celle-ci est répandue, connue en Italie sur ce même type daté de la seconde moitié du I"r s. (Bailey, 1980), pl. 18, Q939, p. 83 et 179$)$.

Type V B1 (pl. 6 et 10)

N"15 (COM.567) : lampe quasi complète; "argile blanche, engobe jatume ".

Longueur : $10,2 \mathrm{~cm}$; diamètre: $7,2 \mathrm{~cm}$.

Trou d'évent circulaire.

Surmoulage au plâtre.

Médaillon : mola asinaria (meule actionnéc par un âne).

Parallèles : ce motif est répertorié en GrandeBretagne daté de la seconde moitié du $\mathrm{I}^{\mathrm{u}} \mathrm{s}$. (Bailey, 1988, pl. 2, Q1508, p. 47 et 158, interprété comme "horse mill"). Il est par ailleurs bien commu par les bas-reliefs ( $c f$ stèle de P. Nonius \%ethus, in : Baat\%, 1995 , p. 10, abb. 9).

N'16 (BUT.65.49) : lampe fragmentaire en pâte beige, engobée en brun-noir; surcuit avec coups de flamme.

Sans trou d'évent.

Diamètre : $6 \mathrm{~cm}$.

Fond à pied simple avec marque en léger relief : I ou trait vertical?

Médaillon : conque.

Parallèles : cette forme de marque est très fréquente, même effectuće par différents potiers ou dans différents ateliers. On peut citer une marque semblable orientée de la même façon à Trèves (Gocthert-Polascheck, 1985, abb. 27, n" 47, p. 179).

Ce thème est présent dès le début du règne d'Auguste, rue des Farges (un exemplaire daté de 30 à 15 avant J.-C. et un autre daté de 15 avant J.-C. à 10 après J.-C.), puis tout au long du $\mathrm{I}^{\mathrm{c}} \mathrm{s}$. (deux exemplaires de l'époque Tibère/Claude et un cxemplaire de la seconde moitié du $\mathrm{I}^{\mathrm{*}} \mathrm{s}$.).

Type V B2 (pl. 6, 7 et 10)

No 17 (COM.553) : lampe complète; "argile blanche, engobe rougeâtre ".

Longueur : 10,7 cm ; diamètre : $7,3 \mathrm{~cm}$.

Fond à pied annulaire.

Surmoulage à l'argile (?).

Médaillon : couronne de feuilles de chêne et glands.

Parallèles : décor déjà connu en Gaule sur type Butte II (Loeschcke I B) daté de 20 à 90 (Bailcy, 1988, Q1491, p. 89) et dans tout l'Empire romain, notamment en Italie sur type I ocschcke V daté du 
début de l’époque flavienne: (Bailey, 1980, Q971, p. 87 et 191).

N"18 (COM.555) : lampe complète; "argile blanche, engobe rouge ".

Longueur : $9,8 \mathrm{~cm}$; diamètre : $7 \mathrm{~cm}$.

Trou d'évent circulaire.

Fond a pied simple avec marque non identifiée en relice.

Pustules de surmoulage et déformation due à une surcuisson.

Médaillon : lion bondissant vers la gauche.

Parallèles : motif apparemment oriental d'après des originaux italiques. Il est connu à Chypre sur type Butte V (I.oeschcke IV) daté de la seconde moitié du Ir s. (Bailey, 1988, (22403, p. 67 et 303).

N"19 (COM.564) : lampe complète; "argile blanche, engobe rouge ".

Longueur : $9,2 \mathrm{~cm}$; diamètre : $6,5 \mathrm{~cm}$.

Trou d'évent circulaire.

Fond à pied simple.

Surmoulage au plâtre.

Médaillon : le corbeau et le renard.

Parallèles : la scène illustre une fable (n"165) d'Esope (Fables : "I ce corbeau et le renard", Les Belles I cettres, 1960), p. 73). D'autres excmplaires lyonnais sont cités par D). M. Bailey (cf. commentaire à propos de la scène d'ailleurs interprétée comme "monkey trying to catch the bird" (Bailey, 1980 , pl. $15, Q 904$, p. 45,75 et 169$)$ et figurant sur type Butte V (I.oeschcke IV) en Italie, daté de 40 à 80). I a même scène est attestéc à Trèves sur type Butte $V$ daté du rène de Claude (Goethert-Polascheck, 1985, taf. 53, motif 76, p. 21) et en Suisse sur type Butte V daté de la seconde moitie du II s. (Iceibundgut, 1977, taf. 37, motif 169 , p. 162$)$.

\section{Type V B3 (pl. 7)}

N" 20 (BUT.65.2) : lampe fiagmentaire en pâte verdâtre déformée et engobe fondu; surcuit.

Diamètre : $7 \mathrm{~cm}$.

Trou d'évent circulaire.

Médaillon : rosette à huit pétales.

Parallèles : dans l'atelier de la Butte, of. n" 3 sur type

Butte I, n" 21 sur le type Butte V B4 et n" 45 (hors typologie); sur le site de la rue des Farges, un exemplaire daté de Tibère/Claude avec le même poincon-décor, deux exemplaires datés de la seconde moitié du I" s., dont un sur le type Butte VI (Ioescheke VIII), et un autre daté de la fin du II's. début III" s. Ce décor est attesté à Vindonissa sur I oeschcke II, I oeschcke V et Butte VI (Ioeschcke, 1919 , taf. I et III, n“" 318, 618 à 672).

\section{Type V B4 (pl. 7)}

N" 21 BUT.65.29) : lampe fragmentaire en pâte pulvérulente, engobéc en rouge.

Diamètre : $6,2 \mathrm{~cm}$

Sans trou d'évent.

Fond à pied simple.

Médaillon : rosette à huit pétales.

Parallèles : cf. Butte 20.

Type V B5 (pl. 7 et 10)

N" 22 (C).M.551) : lampe complète; " argile blanche, engobe jaunâtre".

longucur: $9 \mathrm{~cm}$; diamètre: $6,1 \mathrm{~cm}$.

Trou d'éent circulaire.

Pustules de surmoulage au plâtre.

Fond à pied simple avec marque en creux in planta pedis.

Médaillon : rouelle dont les pétales ne rendent pas compte du motif originel car la lampe est déformée par une cuisson à trop haute température.

Parallèles : cf. Butte 1 ; ce décor, courant sur les productions augustéennes du site de la rue des Farges et de Dangstetten (trois exemplaires de la rue des Farges du contexte 30 a 15 avant J.-C.), a été rencontre au Magdalensberg sur type Butte I (Iocschcke I A) daté d'Auguste (Farka, 1977, taf. 46, n" 245, p. 204) et à Trèves sur type Butte V (Ioescheke IV) (Goethert-Polascheck, 1985, taf. 62, motif 249, n" 457 , p. 276 et 277 ).

N" 23 (C) (O.563) : lampe complète; "argile blanche, cngobe brun".

I ongueur : 8,2 cm ; diametre : 5,6 cm.

Sans trou d'évent.

Fond à pied simple.

Médaillon : pugiliste agenouillé. 
Parallèles : ce motif est fréquent, attesté en GrandeBretagne daté de la seconde moitic du I" s. (Bailey, 1988, pl. 3, Q1532, p. (6l et 161).

\section{Type VI}

Cette forme est bien représentéc dans le dépotoir alors qu'elle est en général peu présente sur le site de la rue des Farges, ayant circulé plus sur le pourtour méditerranéen que dans les provinces occidentales du nord.

L'une des formes produites à la Butte reste très ćloignée des exemplaires de référence du type I oescheke VIII en raison du méplat sur le bandeau (type Butte VI B2), inconnu ailleurs à l'heure actuclle. Elle est done une production originale de la scconde moitić du $\mathrm{I}^{\mathrm{w}}$ s., et celte originalité s’affirme davantage sur les fragments à décor à la roulette (Butte 31) et incisé (Butte 32).

I.es autres variantes du type à bec arrondi sans volutes (Butte VI A et VI C) somt plus courantes, notamment le type Butte VI A employant quasi systématiquement le décor d'oves sur bandeau oblique qui est répertorić dans la plupart des sitesréferences.

\section{Type VI A (pl. 7)}

N. 24 (BUT.65.26) : fragment de bec en pâte jaunc pulvérulente, engobée en brun.

N. 25 (BLT.65.50) : fragment de disque en pâte beige, engobéc en brun ; bien cuit.

Diamètre : $7,8 \mathrm{~cm}$.

Anse moulée avec le corps de la lampe et perforée. Médaillon à décor non identifié.

N"26(BUT.65.43) : fragment de disque en pâte verdâtre ; surcuit.

Diamètre : $6 \mathrm{~cm}$ environ.

Médaillon : rosette à pétales bilobés.

Parallèles : cf. Butte 37 et 38 sur type indéterminé à volutes, et rue des Farges, un exemplaire daté de 15 avant à 10 après J.-C. et un exemplaire daté de Tibère/Claude. Ce motif est moins courant que les rosettes simples. Il existe avec dix pétales à Vindonissa sur type Butte VI (Iocschcke VIII) (Ioeschcke, 1919, taf. III, n"670)).
Type VI B1 (pl. 7 et 10)

N"27 (COM.566) : lampe complete; "argile blanche, engobe jaume ".

Iongueur : $8,3 \mathrm{~cm}$; diamètre : $6,7 \mathrm{~cm}$.

Trou d'écent circulaire.

Médaillon : bouclier, harpon, dauphin.

Parallèles : décor rencontré à Trèves sur une lampe de même fabrication (Gocthert-Polascheck, 1985, taf. 69, motif 43, p. 206, n" 644 avec une anse et n" 697) et a Vindomissa sur Butte VI (Ioescheke VIII) (I ocschcke, 1919, taf. VII, n" 656-57).

Type VI B2 (pl. 7 et 10)

Ce groupe est principalement composé de ce que D. M. Bailey appelle fatties, c'est-à-dire des lampes de grande dimension. I’identification typologique a été effectuée d'après le seul exemplaire de dimension "standard" qui possède son bec (Butte 28) et par analogie au seul exemplaire de ce type attesté sur le site de la rue des Farges (daté de la seconde moitic du I"s.).

N" 28 (BLT.65.9) : lampe fragmentaire en pâte verdâtre et engobe fondu; surcuit.

Diamètre : $7 \mathrm{~cm}$.

Fond à pied simple.

Disque lisse.

N" 29 (BUT.65.7) : fragment de bandeau en pâte pulvérulente beige, engobéc en brun (pl. 10).

Diamètre : $10 \mathrm{~cm}$.

Disque lisse.

Parallèles : type identique à l'exemplaire Butte 28 mais de dimension supéricure. Un exemplaire de ce module, daté de la seconde moitié du I ${ }^{*}$ s., existe sur le site de la rue des Farges.

N" 30 (BUT.65.145) (non illustré cf. n"29) : fragment de bandeau en pâte pulvérulente et engobe brun fondu.

Bandeau à méplat identique aux n“ 29, 31 et 32 avec un sillon supplémentaire.

Diamc̀tre : $10 \mathrm{~cm}$.

No 31 (BLT.65.33) : fragment de bandeau en pâte pulvérulente jaune, engobéc en orange. 
Bandeatu aree décor de bâtonnets (effectué à la roulete) sur le méplat et un sillon supplémentaire. Diamctre: $10 \mathrm{~cm}$.

N"32 (BUT.65.51) : fragment de bandeat en pâte pulvérulente blanche et engobe disparts.

Bandeau identique aux n" 29, 30 et 31 arec décor de cherrons incisés sur le méplat et 1 millon supplémentaire.

Diamctre : $10 \mathrm{~cm}$.

Ce type atteste des imnovations intéressantes. Tout d'abord le type du bandeau est inconnu à l'extéricur de lyon à l'heure actuelle (il est représenté par trois exemplaires sur le site de la rue des Farges dans l'horizon daté de Néron aux Flaviens); de plus, les décors sur méplat sont autant d’innovations uniques, non représentées sur le site de la rue des Farges.

\section{Type VI C1 (pl. 7)}

N"33(BU'T.65.80) : fragment de bandeau en pâte verdâtre ; surcuit.

Diamitre : $7 \mathrm{~cm}$.

Trou d'erent circulaire.

\section{Type VI C2 (pl. 7)}

N"34 (BU'T.65.90) : fragment de bandeau en pâte verdâtre ; surcuit.

Diamòtre : $7 \mathrm{~cm}$.

Trou d'évent circulaire.

Parallòles : la même lampe est commue à Alésia (Carré, 1985, fig. 6, 11"27, p. 291).

\section{MÉDAILLONS HORS TYPOLOGIE}

Cortains fragments de médaillons de lampes qui n'ont pas pu êre identifiés typologiquement présentent néanmoins un intérêt cortain du point de rue iconographique. Certains sont communs et bien diffusés dans les provinces romaines, d'autres sont à l'heure actuclle inconnus à l'extéricur de lyon et ne semblent pas avoir été très diffusés.

\section{Médaillons de formes à volutes (Butte I, II, III ou V)} (pl. 7,8 ct 11 )

Tous ces fragments de disfues décorés somt associés à un bandeau genéralement employe sur des Iypes a volutes. (ertains possedent un ou deux boutons pall volute.

X" 35 (BLT.65.118) : fragment de bandean con pâte pulvérulente jaunc, engobée en rouge.

Bandeau à sillons en bordure.

Médaillon : décor radial de bâtonnets.

Parallèles : Muetue 10 et Butte 51 ; sur le site de la rue des Farges on recense un exemplaire daté de 30 à 15 , deux exemplaires datés de 15 arant J.-C. à 10 après J.C.., deux exemplaires datés de Tibere/Claude, quatere exemplaires datés de la seconde moitic du I" s., dont deux sur type Butte V (Ioeschcke IV) el deux exemplaires datés de la fin duI II"-dlébut III"s.

N’36 (c) 3.562$)$ : lampe fragmentaire; " argile blanche, engobe rouge".

Bandeau à bord droit décoré de trois sillons, les deux derniers ćloignés du premier.

longueur: $8,1 \mathrm{~cm}$; diamère: $7,3 \mathrm{~cm}$.

Fond a pied simple.

Décor du disque : Mars Ultor:

Paralleles : le motif, commun sur les momnaies et sur les lampes, est attesté a Augst sur type Butte V (Iocschcke IV) daté d'Auguste au II: s. (I cibundgut, 1977, taf. 26, motil 34, p. 138, n" 396, p. 243) et en Italie sur ce même type daté de 40 à 75 (Bailey, 1980, pl. 12, Q878, p. 14 et 164), à propos duquel l'auteur cite cet exemplaire lyomais (Butte 36).

N“37 (BL T.65.152) : fragment de disque en pâte beige pulverulente, engobée en rouge.

Bandeau à bord droit décore de trois sillons, les deux derniers éloignés du premier.

Médaillon : rosette à pótales bilobés.

le décor semblant avoir ćé illisible après un surmonlage a ese entionement retrace par incisions apres cuisson ! C"est le seul exemple commu de certe pratique à ce jour ; cette pratique n'est pas forcement adoptée sur des exemplaires voués à la vente puisqu'il s’agit ici de rebuts d'atclier. 
N.38 (BUT.65.153) : fragment de disque en pâte beige pulvérulente, engobée en brun.

Bandeau à bord droit décore de trois sillons, les deux derniers éloignés du premier.

Médaillon : rosette à petales bilobés.

Parallìles : cf. Butte 26 sur type Butte VI et Butte 37, un exemplaire sur type Butte I (Ioeschcke I A) de la rue des Farges daté de 15 avant J.-C. à 10 après J.-C. et un exemplaire du même site daté de Tibere/claude.

N'39 (BUT.65.16) : fragment de disque en pâte pulvérulente blanche, engobée en rouge.

Bandeat à bord droit décoré de trois sillons, les deux derniers éloignés du premier.

Diamètre : $7,8 . \mathrm{cm}$

Ia lampe possede deux trous de remplissage de petite dimension disposés symétriquement par rapport au décor.

Médaillon : motif végétal mal identifié, trois feuilles en bouquet?

Sans parallìle.

N" 40 (BUT.65.31) : lampe fragmentaire en pâte blanche pulverulente, engobée en brun orangé.

Bandeau à bord décoré de trois sillons, les deux derniers éloignés du premier.

Diametre: $7,5 \mathrm{~cm}$.

Fond à pied simple.

Médaillon : couronne de pampres et grappes de raisin.

Parallèles : le motif, courant, est connu sur des lampes italiques type Butte II (Ioeschcke I B) daté de la première moitié du $\mathrm{I}^{\mathrm{w}}$ s. (Bailey, 1980, pl. 4, Q794, p. 88 et 141) et à (arthage sur ce même type (Dencauve, 1969, pl. XI.I, n" 363).

No 41 (BLT.65.5) : lampe fragmentaire en pâte verdâtre et cngobe fondu ; surcuit.

Bandeau à bord droit décoré de trois sillons, les deux derniers éloignés du premier.

Diamètre : $6,5 \mathrm{~cm}$.

Sans trou d'évent.

Fond à pied simple.

Médaillon : oiseau sur branche de grenadier.

Parallèles : ce décor est signalé au Magdalensberg daté des règnes de Tibère/Claude (Farka, 1977, taf. 43 , n" 1096 , motif 135 , p. 139), à Vindonissa à partir du deuxième quart du $I^{\text {" s. }}$ jusqu à la fin du $I^{\cdots}$ s. (I.cibundgut, 1977, taf. 50, motif 483, p. 252, 11" 326, p. 184), cn Italie sur un Iype Butce V' (Iocschcke IV') fabriqué dans l'atelier de Caius Claudius (Mélanges de la Casa Velasquez, 1966, II, pl. VI, n" 38) et à Chypre sur Butte V daté de 40 à 100)(Bailey, 1988, pl. 64, Q2422, p. 81-82 et 305).

N. 42 (BUT.65.37) : fragment de disque en pâte beige, engobéc en orange; bien cuit.

Bandeau à bord droit et trois sillons, les deux derniers éloignés du premier et un décor de tresse entre les deux premiers.

Diamètre: $7 \mathrm{~cm}$.

Médaillon : buste de Mercure.

Paralleles: if. Muctic 11 o $u$ on cxemplaire sur type Butte II (Ioeschcke I B) rue des Farges, daté de la seconde moitié du I ${ }^{\mathrm{c}} \mathrm{s}$.

N 43 (BUT.65.28) : fragment de disque en pâte blanche pulvérulente, engobéc cn brun.

Bandeau à bord droit décoré de trois sillons, les deux derniers éloignés du premicr.

Diamètre : $8 \mathrm{~cm}$.

Médaillon : quadrige vers la droite.

Parallèles : les motifs de quadrige sont attestés, mais tournés vers la gauche, au Magdalensberg sur type Butte I (I.oeschcke I A) (Farka, 1977, taf. 34, n" 335) et 1333 , p. 216 ) et à Toulouse (I andes, 1990, n" 26, p. 241 ct 246$)$.

N" 44 (BUT.65.6) : fragment de lampe en pâte verdâtre et engobe fondu; surcuit.

Bandeau à bord droit décoré de trois sillons, les deux derniers éloignés du premier.

Diamètre : $6,8 \mathrm{~cm}$.

Fond à pied annulaire.

Médaillon : gladiateur (?).

Sans parallèle.

N" 45 (BUT.65.112) : fragment de lampe en pâte pulvérulente rose, engobée en rouge.

Bandeau à bord oblique décoré de deux sillons.

Diamètre : $6,2 \mathrm{~cm}$.

Sans trou d'évent.

Fond à pied simple.

Anse-boudin appliquée après moulage (section ronde).

Médaillon : rosette à 8 huit pétales. 
Parallèles : $\%$. Butte 3 sur type Butte I (Loeschcke I A), Butte 20 et Butte 21.

N" 46 (BUT.65.130) : fragment de disque en pâte beige, engobée en brum ; bien cuit.

Bandeau à bord oblique décoré de trois sillons.

Diamètre : $7,8 \mathrm{~cm}$.

Trou d'event circulaire.

Médaillon : dresseur et cheval (?).

Parallèles : un exemplaire rue des Farges daté de Tibère/Claude. I e poinçon du cheval peut être utilisé scul, comme cela est attesté sur une lampe de Carthage avec la figure retracéc (1)encauve, 1969, pl. XI, n" 346).

N* 47 (BUT.65.69) : fragment de disque en pâte blanche pulvérulente, engobée en brun.

Bandeau à bord oblique décoré de trois sillons.

Diamètre : $7 \mathrm{~cm}$.

Médaillon : gladiateur (?).

Sans parallèle.

N" 48 (BUT.65.I4) : fragments de lampe en pâte verclâtre, engobéc en brun ; surcuit.

Bandeau à bord oblique décoré de trois sillons.

Diamètre : $9 \mathrm{~cm}$.

Fond à pied simple avec marque en relief : V, W ou $\mathrm{M}(?)$.

Médaillon : persommage non identifié en toge.

N" 49 (BUT.65.136) : fragment de disque en pâte pulvérulente blanche, engobéc en brun-rouge.

Bandeau à bord oblique décoré de trois sillons.

Trou d'évent circulaire.

Médaillon à décor non identifić.

N" 50 (BUT.65.121) : fragment de disque en pâte jaune pulvérulente, engobéc en brun.

Bandeau à bord oblique décore de trois sillons, les deux derniers éloignés du premier.

Médaillon à relief très émoussé, décor non identifié ; palmette (?).

Médaillons décorés (pli. 8, 9 cl 11 )

N*ol (BUT.65.157) : fragment de médaillon en pâtc beige, engobée en brun luisant; bien cuit. Médaillon : zone à bâtonnets rayonnant. Parallèles : cf. Muette 10 et Butte 35.
N. 52 (BUT.65.154) : fragment de médaillon en pâte pulvérulente verdâtre, engobée en brun.

Médaillon : feuille de laurier.

Parallèles : of. Butte 53 et un exemplaire du site de la rue des Fanges daté de 15 avant J.-(.. à 10) apres J.-C.

D'après la dimension de la feuille, il pourrait s'agir d'un motif à trois ou quatre feuilles disposées autour du trou de remplissage attesté à lròves sur types Butte III (I.oeschcke I (i) et Butte V (Iocschcke IV) (Dencauve, 1969, pl. XI., n"346).

N".53 (BUT.65.155) : fragment de médaillon en pâte pulvérulente jaune, engobée en rouge.

Médaillon : feuille de laurier.

Parallòles : of. Butte 52.

No 54 (BUT.65.41) : fragment de médaillon en pâte verdâtre et engobe vert luisant ; un peu trop cuit.

Médaillon : Victoire tenant un épi de blé et désignant un bouclier. Grande dimension et facture finc et détailléc.

Parallèles : un exemplaire rue des Farges daté de la seconde moitié du I s. Sur certains exemples lyonnais, le bouclier porte une inscription (Allmer, Dissard, 1888-1893, IV, $n^{\prime \prime}$ l et 4, p. 456-457; Allmer, Dissard, 1887-1888, II, n“ 1472-1473, p. 515; (comarmond, 1855-1857, n"581, p. 99) ainsi que sur des fabrications italiques de type I oeschcke $V$ de la seconde moitié du I"s. (Bailey, 1980, pl. 21, Q957-958, p. 27 et 186-187). Ce motif a été diffusé à Vindonissa sur type Ioeschcke IV du deuxième quart du I" s. à la fin du II" s. (I ceibundgut, 1977, taf. 23, motif 2, p. 133, n" 380, p. 241) et à Carthage sur locschcke IV (Dencauve, 1969, pl. XIVI, 11" 418$)$.

N $35.5,56$ et 57 (BUT.65.17, 65.18 et 65.106) : fragments de medaillon en pâte verdàtre et engobe fondu; surcuit.

Médaillon : Éros sur chèvre.

Saus parallìle.

I ces trois fragments de ce même décor ont été fabriqués avec le même poinçon ou dans le même moule.

N"58(BUT.65.22) : fragment de médaillon en pâte blanche pulvérulente, engobée en brum.

Médaillon : Éros jouant avec un animal. 
Parallèles : deux exemplaires de la rue des Farges datés de la seconde moitié du I" s. et un exemplaire daté du II*s.

Ia scène est commuc à Vienne (Trial, 1988, décor 103, pl. 37). Ce décor, commun, a circulé dans tout l'Empire sur types Butte I, II, III ou V (Ioeschcke I ou IV), notamment à Vindonissa et à Augst, de Tibère à la fin du II* s. (I oeschcke, 1919, taf. IV, n" 12 à 16 ; Lcibundgut, 1977, taf. 30, motif 84, n" 158 à 160 et n" 412, p. 147), à Trèves sur Butte II (Loeschcke I B) (Goethert-Polascheck, 1985, taf. 22, motif 9, p. 194, n"175), au Magdalensberg daté de la première moitié du I ${ }^{\mathrm{c}}$ s. (Farka, 1977, taf. 28, n" 1287, motif 12, p. 109) et à Carthage (Deneauve, 1969, pl. I.XVI, n"661).

No59 (BLT.65.150) : fragment de médaillon en pâte pulvérulente jaune, engobéc en brun.

Médaillon : gladiature; maître d'armes séparant des gladiateurs.

Parallèles : la scène est présente à Trèves avec un cartouche donnant le nom des deux combattants sur type Butte II ou V (Loeschcke I B et IV) daté de l'époque Claude/Néron au début des Flaviens (Goethert-Polascheck, 1985, taf. 30 et 54, motif 85, p. 220) et à Vindonissa sur types Butte I, II ou III (Loeschcke I) (Loeschcke, 1919, taf. XV, n" 113, p. 370).

$N^{\circ} 60,61$ et 62 (BLT.65.19, 65.78 et 65.107) (les $n^{\prime \prime 61}$ et 62 ne sont pas illustrés) : fragments de médaillons en pâte jaune pulvérulente, engobée en orangé.

Médaillons : jockey.

Ce décor du jockey (jubilator) aux courses des Jeux Apollinaires (Ludi Apollinares) est représenté dans le dépotoir sur trois fragments différents fabriqués avec le même poinçon ou le même moule.

Parallèles: D. M. Bailey cite ces exemples lyonnais fabriqués dans l'atelier de la Butte et il en mentionne deux que A. Comarmond a répertorié dans son catalogue. I e motif issu du même poinçon est présent sur deux excmplaires du site de la rue des Farges, datés de la seconde moitié du II* s. Il est connu aussi à Montans sur type Butte V (Loeschcke IV) daté de la seconde moitié du I $\mathrm{I}^{\mathrm{c}} \mathrm{s}$. (I andes, 1990, n"28, p. 242 et 247), à Vindonissa sur Butte II et V (I oeschcke I B et IV) du deuxième quart à la fin du I" s. (Iooschcke, 1919, taf. IX, n" 99 à 101 ; I ceibundgut, 1977, taf. 44, motif 247 , $n^{\prime \prime} 251$ à 254 et 453) el en Italic, mais fabriqué avec différents poinçons sur type Butte III (Loescheke I C) daté de 40 à 80 (Bailey, 1980, pl. 5, Q802, p. 5859).

N" 63 (BUT.65.76) : fragment de médaillon en pâte verdâtre; surcuit.

Médaillon : bige tourné vers la gauche.

Parallèles : quatre exemplaires de la rue des Farges datés de la seconde moitié du I ${ }^{\mathrm{w}}$ s., dont deux sur type Butte III (I oeschcke I ( ) issus de poinçonsdécors différents, et deux certainement issus du même poincon bien que difficilement lisibles car certainement surmoulés au plâtre. On trouve aussi ce même poinçon à Vindonissa et Augst sur type Butte II (Iocschcke I B) à partir de Tibère jusqu'à la fin du I" s. (Iocschcke, 1919, taf. X, n" 157 ; Icibundgut, 1977, taf. 43 , motif $237, n^{\prime \prime} 157$ à 162 ct n" 247, p. 171).

N" 64 (BUT.65.77) : fragment de médaillon en pâte jaunc à engobe brun fondu.

Médaillon : cavalier (ou cavalière) monté cn amazone.

Sans parallèle.

N" 65 (BUT.65.75) : fragment de médaillon en pâte verdâtre; surcuit.

Médaillon : femme nuc; après comparaison avec un exemplaire de la rue des Farges de l'époque Tibère/Claude, identifié comme scène érotique.

Parallòles : un exemplaire de la rue des Farges daté de Tibère/Ciaude et un excmplaire du même site daté de la seconde moitié du Ir s.

Cette scène est courante, connue à Vindonissa sur type Butte V (Iocschcke IV) (Loeschcke, 1919, taf. VIII, n"- 402 à 405), à Augst (I cibundgut, 1977, taf. 38, motif 179, n" 434, p. 163) et aul Magdalensberg daté du règne de Tibère à celui de Claude (Farka, 1977, taf. 33, n"1249), en Italie sur type Butte $V$ daté de 40-80 (Bailey, 1980, pl. 18, Q935, p. 178) et à Carthage sur type Butte III (Loeschcke I C) (Dencauve, 1969, pl. XXXIX, n"336).

N" 66 (BUT.65.151) : fragment de médaillon en pâte pulvérulente verdâtre, cngobée en brun. 
Médaillon : petit persomage nu (Éros ?) ; scène non identifices.

\section{Type VII (pl. 9 et l1)}

Ces veilleuses sont de même fabrication, au point de reproduire le même motif décoratif, bien que quelques minimes differences dimensionnelles soient à noter, certainement dues au degré de rétraction de l'argile qui dépend de la cuisson. I'exemplaire Butte 71 n'est peut-être pas fabriqué dans le même moule, mais il est issu du même poinçon que les autres exemplaires.

N"67 (COM..543) : veilleusc complète en pâte rosâtre engobéc en orangé.

Longueur : $6,9 \mathrm{~cm}$; largeur : $4,1 \mathrm{~cm}$.

Trou d'event circulaire.

Médaillon : conque à cinq branches.

Parallèles : même fabrication que les exemplaires Butte 68 à 71 et qu'un exemplaire similaire (de type, dimensions et décor identiques) de la rue des Farges daté de 50-60) (que l'on est tenté d'attribuer aussi à l'atelier de la Butte). Lautelier en a certainement fabriqué plusieurs séries quasiment identiques au vu des quatre autres exemplaires fabriqués avec le même moule. (Ce type associé à ce décor est présent à Vienne avec un bandeau à bord droit et un décor de conque à dix branches, retracé (Trial, 1988, pl. 57, n"3), au Magdalensberg avec un bandeau à bord droit décoré de deux sillons et un médaillon portant une conque à onze branches daté du règne de Claude (Farka, 1977, taf. 25, 11" 1460), p. 95 et 326), en Italie avec un décor de conque à onze branches daté de la seconde moitić du I" s. (Bailey, 1980), pl. 42, Q1117, p. 250) el à Carthage avec un bandeau à bord droit décoré d'un sillon ce d'une conque à six branches, type daté du début de la seconde moitié du I"- s. (Dencauve, 1969, pl. I.XVII, n" 696 et table typologique, pl. XVI).

N"68 (COM.544) : veilleuse complète en pâte rosâtre, engobée en orangé.

Longueur : $7,1 \mathrm{~cm}$; largeur : $4,2 \mathrm{~cm}$.

Médaillon : conque à cinq branches.

Parallèles : cf. Butte 67, 69, 70 et 71.
No69(C)M.545) : veilleuse complète en pâte rosâtre, engobée en orangé.

Longucur : $6,9 \mathrm{~cm} ;$ largeur : $4,2 \mathrm{~cm}$.

Médaillon : conque à cing branches.

Paralleles: 19 . Butte $67,68,70$ et 71 .

N*70 (COM.546) (non illustré) : veilleuse complète en pâte rosâtre, engobée en orangé.

Longeur : $6,8 \mathrm{~cm} ;$ largeur : $4,1 \mathrm{~cm}$.

Médaillon : conque à cinq branches.

Parallèles : of. Butte $67,68,69$ et 71 .

N*71 (BUT.65.34) (non illustré) : veilleuse fragmentaire en pâte rosée, engobée en orange; bien cuite.

Longucur : $5,5 \mathrm{~cm} ;$ largeur : $4 \mathrm{~cm}$.

Sans trou d'évent.

Médaillon : conque à cinq branches.

Parallèles : $c$. Butte $67,68,69$ et 70 .

Type VIII (pl. 9 ( \& 11)

N.72 (C., (O..549) : veilleuse complete; " argile blanche, sans engobe ".

Bandeau décoré d'oves tournés vers l'extérieur.

I.ongueur : $7,1 \mathrm{~cm}$; diamètre : 4,2 cm.

Sans trou d'évent.

Médaillon : buste de Sćléné arec croissant sur la tôte.

Parallèles: ce type de veilleuse est fréquent à Albala-Romaine arec décor d'oves sur le bandeau mais disque sans figuration (Avala, 1990, p. 205 et 206, $\mathrm{n}^{\prime \prime} 120$ à 123, fig. 18) ct d'autres veilleuses affichant ce même thème représenté avec le buste de Séléné dans un croissant ou un simple croissant de lune (Ayala, 1990, p. 203 et 205). I. même type de lampe existc à Vindomissa (Loeschcke, 1919, taf. III, 11" 638) et on trouve le même décor en Numidie sur upe Butue VI (Loescheke VIII) daté de la première moitic du II" s. (Bailcy, 1988, pl. 12, Q1672, p. 17 (t 177).

No 73 (BUT.65.144) : fragment de veilleuse en pâte jaunc pulvérulente, engobéc en orangé.

Parallèles : deux exemplaires du site de la rue des Farges datés de 70-90).

Il apparaît, d'après la répartition typochromologique des lampes du site de la rue des Farges et les parallèles effectues, que la production du type 
Butte VII, ponctuelle, commence avant celle du type Butte VIII qui perclure au moins jusqu’à la fin du II s. (trois exemplaires de la me des Farges datés de fin II"s.-début III"s.). Notons la présence du type Butte VII et l'absence de Butte VIII au Magdalensberg, site abandomé à la fin du règne de Claude. Pour ce qui concerne la datation du dépotoir de la Butte, on la situe au plus tard au début de la production des types VII, c'est-ì-dire dans la première moitić de l'époque flavienne.

\section{IMITATIONS DE LAMPES DE FIRME}

Dans la seconde moitic du I" s., un noureau type de lampe se diffuse, la "lampe de fime " créée en Italie à partir de pâtes siliceuses et immédiatement reproduite, notamment en Gaule. ì Iyon, l'utilisation traditionnelle d'argiles calcaires pour la céramique fine se maintient pour la fabrication de ce type de lampes mais elles sont engobées pour imiter l'aspect rouge ou orangé des productions italiques.

I a faible proportion de cet échantillon par rapport aux autres types peut indiquer que la constitution du dépotoir s'effectuc au plus tard au tout début de la production des lampes de firme.

Type IX (pl. 9 et 11)

N"74 (BUT.65.12) : lampe fragmentaire en pâte blanche pulvérulente, engobéc en brun.

Ailerons latéraux trilobés.

Diamètre : $6 \mathrm{~cm}$.

Pustules de surmoulage au plâtre.

Fond à pied annulaire doublé d'un sillon, avec marque en relief issuc d'une estampille: ISPAM et croix à trois branches en dessous.

Sans parallèle.

Disque lisse.

N"75 (BUT.65.13) : lampe fragmentaire en pâte blanche pulvérulente, engobéc en brum.

Ailerons latéraux à cinq lobes.

Diamètre : $5 \mathrm{~cm}$.

Fond en retrait avec marque en relicf : C. FADI.

Parallèles : la signature C. FADI du potier Caius Fadius est connue sur une imitation de Ioescheke
IX C à Vaison-la-Romainc (Bailly, 1962, p. 88 et 95 , 1" 1), signéc en relief mais résultant d'une incision dans le moule (alors que colle de la Butte a été estampillée) et sans point après le (i. Elle est datéc de la seconde moitic du $\mathrm{I}^{\prime \prime} \mathrm{s}$.

Cette référence de Vaison-la-Romaine est identique à la signature d'un fragment découvert dans le dépotoir ménager du Bas-de-I oyasse de fabrication padane de l’époque flavienne. (On retroure aussi cette signature sur une lampe de fabrication padane des fouilles de Trion (Allmer, I)issard, 1887 1888, II, n' 22 et 1442, p. 461 el 509).

Il semble que Caius Fadius soit un potier italien qui signe sa production arec une estampille au milicu du I" s. Cette signature est reprise par un potier lyonnais, effectuéc avec une estampille différente peut-être sturmouléc ?

Disque lisse.

En fait, ce type "hybride" annonçant le type loescheke IX canonique (type Butte X), dont la forme se stabilise, pensons-nous, peu de temps après ces premières productions, remplace les ailerons de tradition tardo-républicaine par des bossettes percées ou non sur le bandeau.

Nous savons aussi que ce type particulier est une imitation de lampe de firme padane puisqu'un excmplaire de fabrication padane est attesté à Vienne (Trial, 1988, décor 181, pl. 52). I'exemplaire de Vienne est en pâte siliceuse rouge très lissée sans engobe, technique adoptéc et conservéc pour toutes les productions de ce type en Italie du Nord. De plus, il porte deux ailerons latéraux trilobés, ornés de petits cercles, et une signature non identiliée sur un fond très mouluré : FERAC..., PERAC... ou HERAC... :

Une autre lampe de type précoce produite en Italic du Nord a été découverte au Magdalensberg (Farka, 1977, taf. 23, n"1447, p. 80 et 324). Elle se trouvait dans un niveau qui précède légèrement le milicu du $\mathrm{I}^{\mathrm{s}} \mathrm{s}$. Enfin, une lampe semblable de type Loeschcke IX B est présente à Vindonissa (Locschcke, 1919, abb. 43, n" 2, p. 471). Ces deux exemplaires de la Butte sont les seuls qui attestent une imitation de type Iocscheke IX italique précoce et, d'après Farka, nous nous autorisons à dater cette fabrication du règne de Néron. 


\section{Type X}

Il faut mentionner deux fragments de bandeau à bord oblique portant un bourrelet et des bossettes (non percées), qui caractérisent les lampes de firme et leurs imitations attribuables aux types I.oeschcke IX ou Loescheke X selon leurs types de bec.

Ces deux fragments témoignent d'une production d'imitation de lampe de firme de type standard (certainement Ioeschcke IX). Le début de cette production est datée dans les autres atcliers provinciaux du règne de Vespasien (Farka, 1977, p. 81 ct 82). Ce type nous donne un terminus ante quem pour la constitution du dépotoir étant le dernier type produit chronologiquement que nous situons donc dans la première partie de l'époque flavienne, ce qui confirme la datation avancée d'après l'étude des types Butte VII et VIII.

\section{Les marques (pl. 9)}

\section{Marque en creux}

N"76 (BUT.65.147) : fragment de fond en pâte pulvérulente jaune et engobe fondu.

Fond a pied simple avec une marque en creux in planta pedis sans inscription.

Parallèles : elle se trouve aussi sur l'exemplaire Butte 22, de type Butte VI, et elle a pu être créce originellement avec le même poinçon-matrice dans des moules différents. Mais en ce qui concerne nos deux exemplaires, la forme de cette marque non inscrite semble être le résultat de l'évolution ou du surmoulage des marques in planta pedis (Bailey, 1980, lig. 111). Ce type d'empreinte en forme de pied est connu sur une lampe de type Butte VI (Loescheke IV) à Vaison datée du milieu du I" ${ }^{\mathrm{F}} \mathrm{s}$. (Bailly, 1962, p. 124 et 125, 11" 15) el sur des lampes à médaillon de Trèves (Goethert-Polascheck, 1985, abb. $2,11^{\prime m} 50$ (t 51 , p. 179).

\section{Marques en relief}

N. 77 (BUT.65.73) : fragment de fond en pâte verdâtre à engobe brun fondu.

Fond à pied simple avec marque centrale en relief produite après incision dans le moule en forme de
X ou de croix?

Sans parallèle.

N"78 (BUT.65.72) : lampe fragmentaire en pâte jaune pulvérulente et engobe rouge fondu.

Pustules de surmoulage au plâtre.

Fond à pied simple avec marque centrale en relief tronquée en forme de $\mathrm{X}$ ou de croix?

Parallèles : type Butte VI; elle est proche de la marque présente sur un fragment de fond de la rue des Farges daté de la seconde moitié du I $\mathrm{I}^{\mathrm{k}}$ s.

No 79 (BUT.65.94) : fragment de fond en pâte verdâtre et engobe brun fondu.

Pustules de surmoulage au plâtre.

Fond à pied simple avec marque centrale en relief produite après incision dans le moule, fait identifiable d'après la finesse des traits. Forme de X ou de croix à branches allongées jusqu'au sillon marquant le fond.

Sans parallèle.

N" 80 (BUT.65.40) : fragment de fond en pâte beige pulvérulente, engobée en brun.

Fond a pied simple avec marque centrale en relicf en forme de $\mathrm{X}$ ou de croix à branches allongées jusqu'au sillon marquant le fond.

Sans parallèle.

N" 81 (BLT.65.10) : fragment de fond en pâte beige et engobe rouge fondu.

Surmoulage à l'argile (?) ayant émoussé le relief.

Fond à pied simple avec marque en léger relief représentant un trait vertical et un trait aux deux extrémités courbées, qui peuvent être identifiées comme les lettres I et $S(?)$.

Parallèles : ce signe pourrait facilement être rapproché de celui que porte l'exemplaire Butte 7 si ce dernier n’était pas en creux. Néanmoins, la marque de Butte 81 provenant certainement d'un surmoulage, Butte 7 pourrait être l'un des exemplaires surmoulés ?

N" 82 (BUT.6.5.135) : fragment de fond en pâte verdâtre (') engobe brun fondu.

Fond a pied simple avec marque très en relief de la forme d'un triangle dont la médiane est marquée. Sans parallèle. 


\section{DIFFUSION DES LAMPES MARQUÉES}

Ces signatures ne sont pas attestées hors de Lyon ; les autres marques semblent pareillement peu diffusées, absentes du site de consommation (rue des Farges) et sans référence bibliographique.

Néanmoins, la diffusion de nombreuses lampes lyonnaises est attestée sur les sites de Rhétie, notamment à Vindonissa (Loeschcke, 1919, p. 252-254; Schneider, Wirtz, 1992). Or, même destinćes à l'exportation, les lampes n'étaient ni signées ni marquées. Et, bien qu'il soit délicat d'en donner une interprétation, la présence ou l'absence de marque ne paraît pas avoir d'incidence déterminante sur la diffusion des produits. Les lampes marquées pouvaient porter ce signe de reconnaissance sclon leur destination géographique et commerciale.

\section{Conclusion}

Comme dans l'atelier de la Muette, la production en série est attestée par la présence redondante d'exemplaires fabriqués dans un même moule (Butte 55, 56 et 57 , Butte 60,61 et 62 et Butte 67, 68,69, 70 et 71) (pl. 11) ou portant un même motif : n“ 60 à 62 (pl. 9).

Le type Butte VII, avec cinq exemplaires de même facture, fabriqués à l'aide du même moule, semble avoir été peu diffusé et est donc peut-être réservé à la région proche. Ces cinq exemplaires similaires, dont un provient des découvertes anciennes de chez M. Morel, confortent l'hypothèse d'un même atelier.

Tous les types circulant dans le courant du I's $s$. (excepté le type Loeschcke V) sont représentés dans ce dépotoir. Lc type Butte V est majoritaire et serait donc le plus fabriqué, mais cette réalité est à mettre en relation avec la durće de sa production : son équivalent (Loeschcke IV) circule en effet en occident romain depuis Tibère jusqu'à Trajan. En outre, l'absence du type précoce Muette I et la faible représentation des types Butte VA de facture fine caractéristiques de l'époque tibérienne incitent à considérer le type Butte I comme résiduel dans ce dépotoir et à situer chronologiquement sa constitution un peu plus tard.

D'après la fréquence des types, on date l'activité de l'atelier liće au seul dépotoir concerné, entre la fin du règne de Claude et le début de l'époque flavienne (5085).
Ices motils des lampes à médaillon sont généralement communs, avec toutefois quelques exceptions (par excmple l'Éros sur une chève des n" 55 à 57 pl. 11) qui ne sont pas non plus représentées sur le site de la ruc des Farges. Ceux-ci pourraient ĉtre, comme les exemplaires décorés à la roulette ou à chevrons incisés (pl. 7, n“31 et 32), des innovations propres à l'atelier dont la tentative de mise sur le marché aurait échoué.

S. E.

\section{LES AUTRES PRODUCTIONS}

\section{LES MORTIERS}

Parmi le matéricl recucilli sur le site figure également un mouton, constitué par un mortier fondu, collé sur des tuiles déformées (fig. 13).

Il s'agit d'un mortier à marli, presque horizontal, légèrement recourbé, apparenté aux types Vindonissa 575 et 576. Ce type peu fréquent à Lyon se retrouve dans le matériel de la Manutention ( $c f$ infra, p. 46).

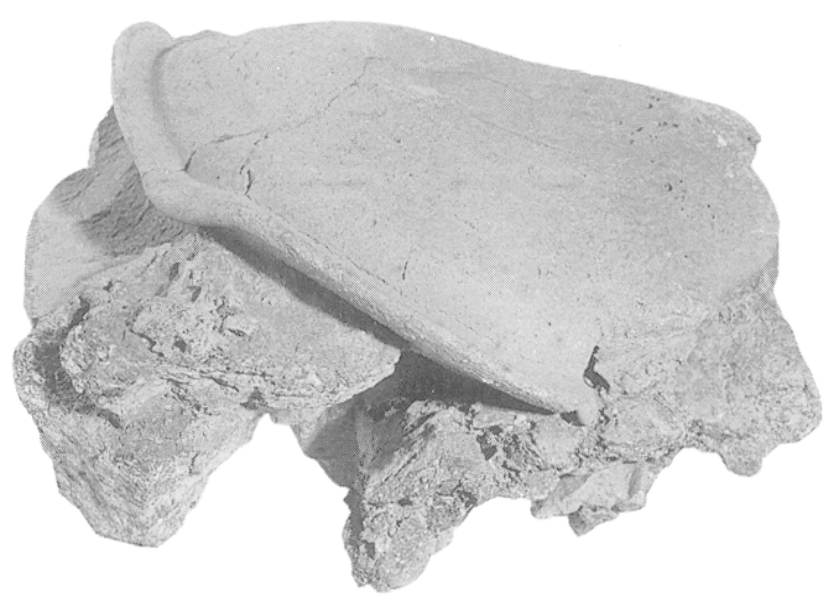

Fig. 13. Mortier fondu (mouton) de l'atelier de la Butte (échelle : $3 / 10)$.

\section{LES BOUCHONS D'AMPHORES (fig. 14)}

I.e matériel récolté comporte encore plusieurs de ces vases appelés quelquefois amphorisques et considérés comme des bouchons d'amphores. 

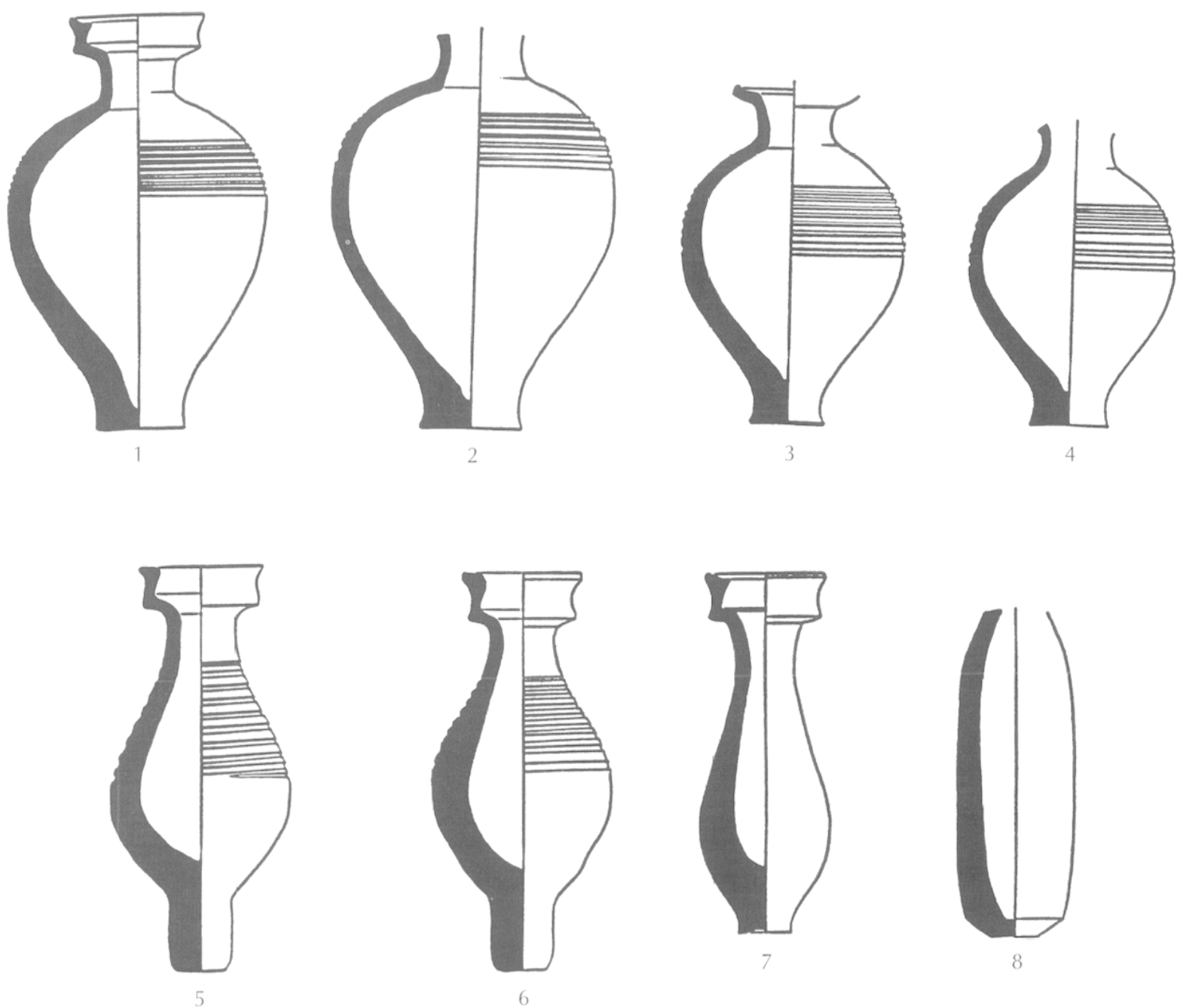

Fig. 14. Les bouchons d'amphomes de latelier de la Bulle (échelle: 1/3), (dessin E. Ber(rand).

Ie rapport de $A$. Grange signale, dans une tranchée latérale, exécutée vers l'est (parallèlement au quai), la découverte de : "plusieurs amoncellements de vases considérés comme bouchons d'amphores, de plusieurs calibres " $"$. Les exemplaires qui nous sont parvenus ne presentent pas de traces de surcuisson, mais leur concentration, ainsi que la composition des exemplaires analysés concourent à en faire une production locale (fig. 14). Lielentification de ce type de vases ave des bouchons d'amphores a écé proposée au départ par S. I.oeschcke (1939). On a voulu confirmer cette interprétation en s'appuyant sur la décourerte d'un exemple conservé

5. Rappert dactrlegraphic adressé par André (Grange a la Direction des Antiquites historiques le 19.03.1969. dans le col d'une amphore de Saint-Cyr-sur-Mer (Benoit, $1956)$ et sur celle des trois amphores de l'epave d'Albenga bouchées arec un tampon de liège dans lequel était enfoncée une pomme de pin. Ce système a été considere en quelque sorte comme un prototype des bouchons en céramique (Vegas, 1973, p. 56).

Cette hypothèse reprise par de nombreux auteurs n'a pas fait l'unanimité et divers autres usages ont été proposés : ventouses pour extraire les bouchons d'amphores (Rodrigue\%-Almeida, 1986), éléments pour la construction de voûtes, unguentenia, éléments de lampadaires, et même des comets pour jouer aux dés (Pavolini, 1980). Aucune de ces hypothèses ne parât crédible et bien que, comme ke rappelle C. Pavolini (1980, p. 1010), aucun amphorisque n’ait été retrouvé en place dans le col 
d'une amphore à Pompéi, l'hypothèse de bouchons nous paraît la plus vaisemblable.

\section{Les formes}

Huit exemplaires presque complets ont été conservés au musée. Ils présentent tous le même type d'embouchure, avec une lèvre en bandeau incurvée, débordante, sur un col court et étroit.

I a forme de la panse et du fond permet de les classer en quatre types:

- Ie premier est constitué de quatre exemplaires avec une panse arrondic, plus ou moins globulaire, se terminant par un fond plat étroit (fig. 14, n" 1 à 4). I.es stries horizontales sont disposées sur le haut de la panse.

- Ie deuxième ne compte que deux exemplaires (fig. 14, n"5 et 6), avec une panse allongée s'élargissant vers le bas et terminée par un petit pilon. Des stries horizontales garnissent également la panse.

- Ice troisième ne comprend qu'un seul exemplaire (fig. 14, n"7) avec une panse allongée, s'élargissant vers le bas mais terminée par un petit fond plat. Ia panse est lisse.

- Ie quatrième, également représenté par un unique exemplaire (fig. 14, n"8), comporte une panse allongée terminée par un fond plat raccordé à la panse par un biscau.

I ces deux derniers types, qui ne comptent qu'un excmplaire, sont par ailleurs rares sur les sites de consommation. En revanche les types 1 et 2 se rencontrent fréquemment sur les sites lyonnais dans des contextes des I" et II"s.

En dehors de I,yon, le type 2 semble largement diffusć et on peut citer de nombreuses références :

en Espagne: Vegas, type 61, fig. 1 ; Beltran Lloris, 1970, type e;

à Angers : Siraudeau, 1988, n“ 0018 à 0021 ;

à Ostie: Pavolini, 1980, groupc D2, types 16 et 17 . I a datation fournie par le site d'Ostie coïncide avec celle des sites lyonnais : de la seconde moitié du $I^{{ }^{*}} s$ s. à la fin du II's.

I a confirmation par les analyses d'une origine locale permet de rapprocher la fabrication de ces bouchons de la production d'amphores à Iyon. Ia diversité des formes suggère qu'ils correspondent à plusieurs types mais la correspondance reste à établir.

A. D.

\section{CARACTÉRISTIQUES CHIMIQUES DES PRODUCTIONS}

Une séric d'analyses portant sur 20 exemplaires de lampes, céramiques à parois fines et colifichets a été effectuée en mesurant uniquement les huit constituants chimiques majeurs. Parmi ces exemplaires nombreux sont ceux qui ont subi des altérations de leur composition chimique lors de l'enfouissement. Ils ne sont donc pas utilisables pour définir les caractéristiques de l'atelier. On remarque cependant l'existence des deux types d'argiles calcaires, alors que l'on avait remarqué à la Muette une disparition des pâtes très calcaires aux périodes tardives.

Le tableau I donne à titre indicatif la moyenne et l'écart-type des compositions chimiques pour les deux types d'argile.

Ces compositions chimiques sont très proches de celles des ateliers de la Muette. Ceci est dû à une origine géologique commune des argiles prélevées dans les formations alluviales rhodaniennes.

A. S.

Tabl. I. Comprosition chimique moyenne des lampes de l'atelier de la Butte.

Éléments majeurs en pourcentages d'oxydes

\begin{tabular}{|c|c|c|c|c|c|c|c|c|}
\hline $\begin{array}{c}\text { La Butte } 1 \\
(\mathbf{n}=7)\end{array}$ & $\mathrm{K}_{2} \mathrm{O}$ & $\mathrm{MgO}$ & $\mathrm{CaO}$ & $\mathrm{MnO}$ & $\mathrm{Al}_{2} \mathrm{O}_{3}$ & $\mathrm{Fe}_{2} \mathrm{O}_{3}$ & $\mathrm{SiO}_{2}$ & $\mathrm{TiO}_{2}$ \\
\hline $\mathrm{m}$ & 2 & 2,2 & 14,4 & 0,112 & 18,9 & 7,3 & 54,2 & 0,72 \\
\hline$\sigma$ & 0,4 & 0,3 & 2,5 & 0,021 & 2,1 & 0,4 & 1,8 & 0,08 \\
\hline$\sigma \%$ & 18 & 12 & 17 & 19 & 11 & 5 & 3 & 11 \\
\hline
\end{tabular}

Éléments majeurs en pourcentages d'oxydes

\begin{tabular}{|c|c|c|c|c|c|c|c|c|}
\hline $\begin{array}{c}\text { La Butte 2 } \\
(\mathbf{n}=8)\end{array}$ & $\mathbf{K}_{2} \mathrm{O}$ & $\mathbf{M g O}$ & $\mathrm{CaO}$ & $\mathrm{MnO}$ & $\mathrm{Al}_{2} \mathrm{O}_{3}$ & $\mathrm{Fe}_{2} \mathrm{O}_{3}$ & $\mathbf{S i O}_{2}$ & $\mathbf{T i O}_{2}$ \\
\hline $\mathbf{m}$ & 2,2 & 2 & 20,1 & 0,114 & 14,2 & 5,6 & 55,2 & 0,56 \\
\hline$\sigma$ & 0,3 & 0,2 & 1,6 & 0,008 & 1,6 & 0,6 & 3,1 & 0,034 \\
\hline$\sigma \%$ & 13 & 12 & 8 & 7 & 11 & 11 & 6 & 7 \\
\hline
\end{tabular}

$*$

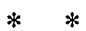


Le site de la Butte a fourni les traces d'unc activité céramique diversifiée qui comprend quatre catégories de céramiques : parois fines, lampes, mortiers et bouchons d'amphores.

Les témoins recueillis lors des fouilles de 1965 nc donnent à l'évidence qu'un aperçu des productions de l'atelier qui devait s'étendre sur une surface importante et dont la période d'activité a dû couvrir une période plus longue que celle déterminée à partir des productions récoltées.

Les éléments chronologiques fournis par les différentes catégories permettent de conclure que l'atelier a fonctionné durant la seconde moitié du I ${ }^{\mathrm{rr}} \mathrm{s}$. Toutefois, les études effectuées sur les sites de consommation comme la rue des Farges (Grataloup, 1984 ; Elaigne, 1993) ou Saint-Romain-en-Gal (Desbat et al., 1994) mon- trent que la période d'activité de l'atelier de Iyon est beaucoup plus longue, sans que l'on puisse dire si elle a été limitée au site de la Butte ou s'il a existé à proximité d'autres sites producteurs.

À partir des sites de consommation anglais et rhénans, K. Greene (1979) avait situé l'activité de l'atelier de Lyon entre $30 \mathrm{ct} 70$, date de l'arrêt des importations, notamment à Usk. Cet arrêt avait été mis en relation avec une disparition de l'atelier qui aurait pu être consécutive aux troubles qui avaient suivi la mort de Néron en 68 après J.-C. On sait aujourd'hui qu'il n'en est rien et que les productions de lampes à huile et de parois fines à pâte calcaire ont commencé dès le règne de Tibère et se sont poursuivi jusqu'au II" $s$.

A. D. 

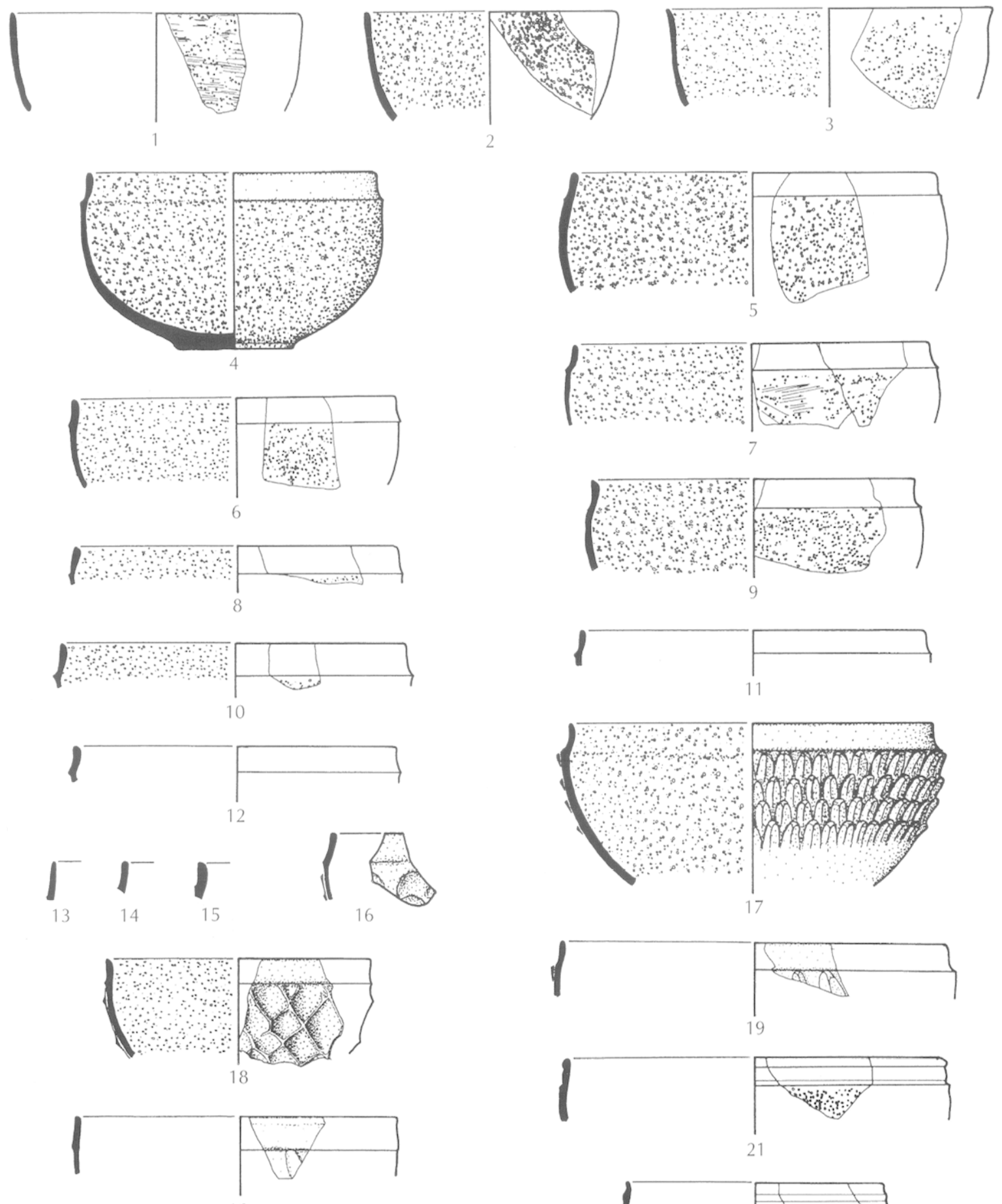

20
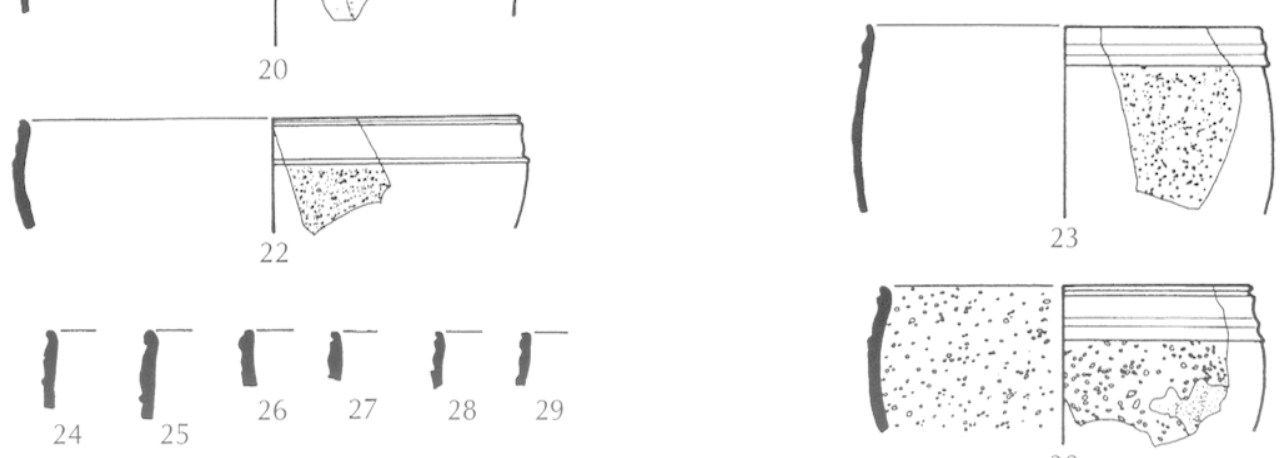

30

P1. 1. Les céramiques à parois fines de l'atelier de la Butte (échelle: 1/2). 

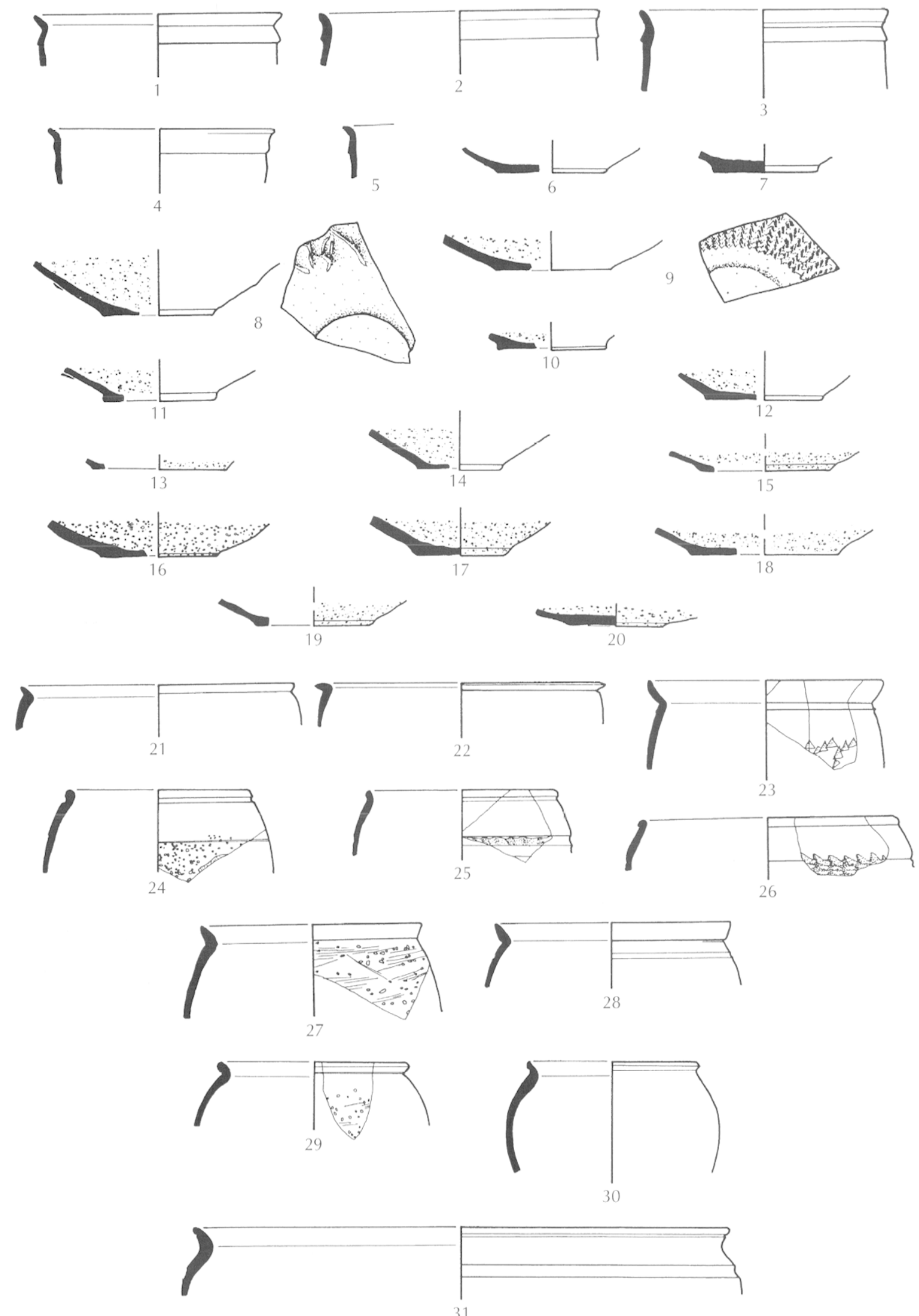

P1. 2. Les céramiques à parois fines de latelier de la Bulle (échelle: I/2). 
广
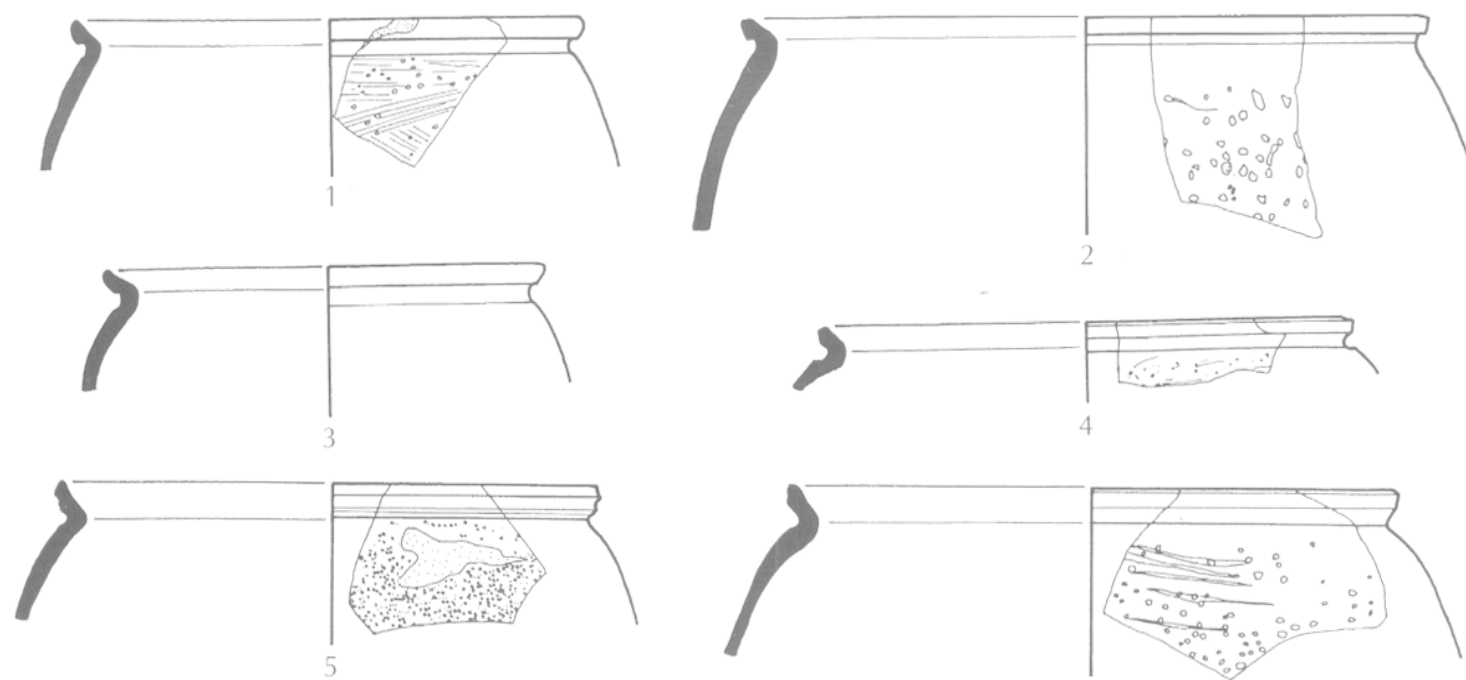

6
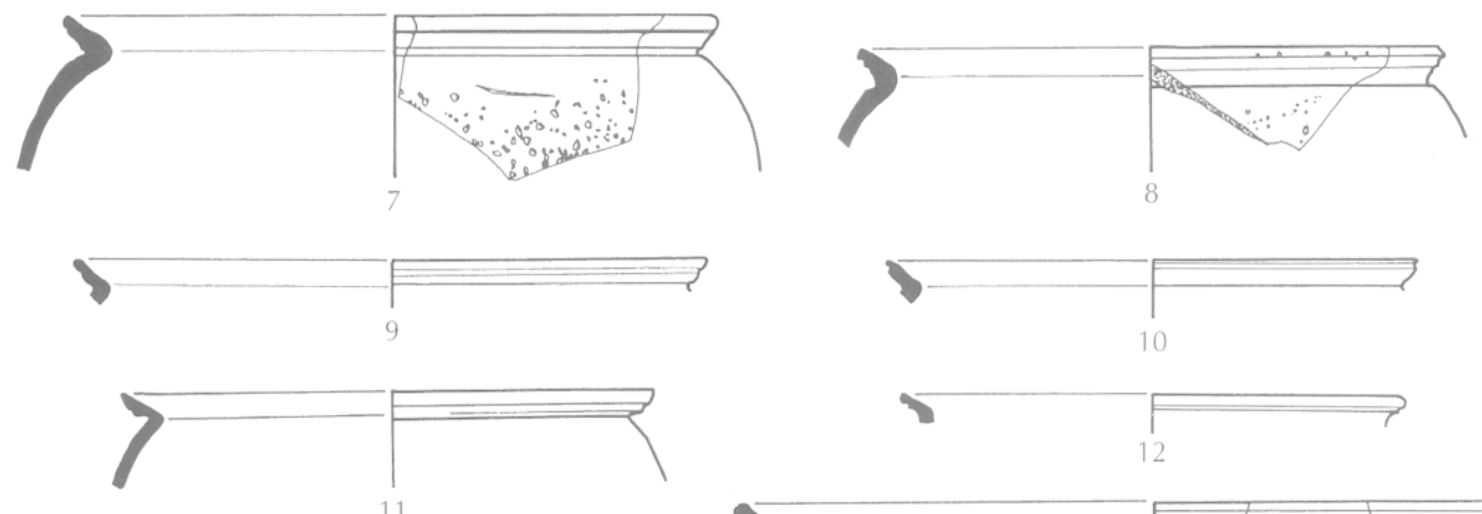

11
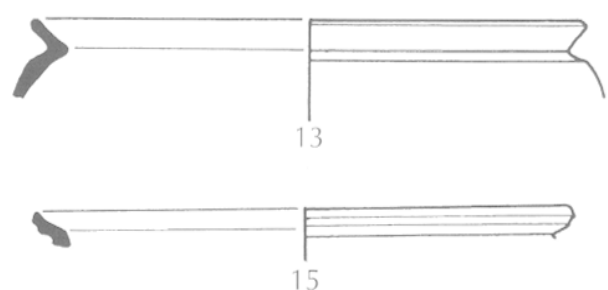

15

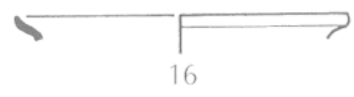

$>$

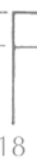

$>$

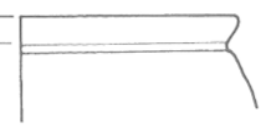

20

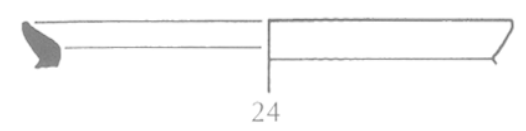

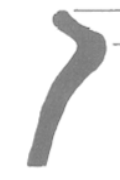

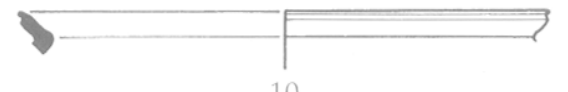

10
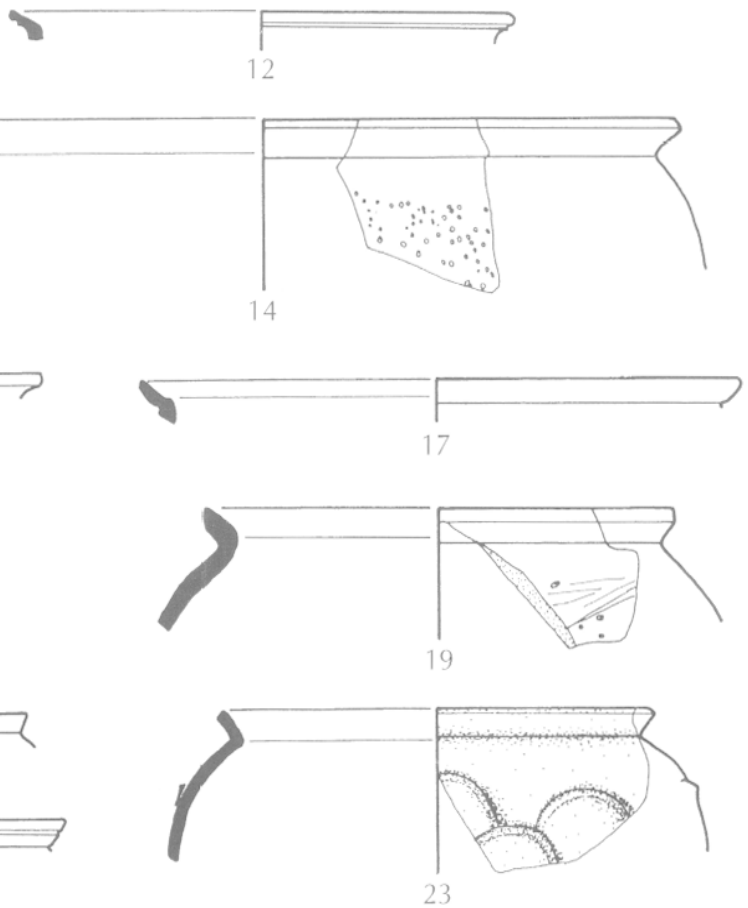

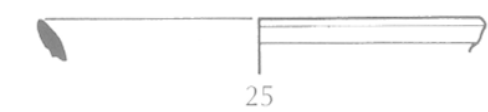

25

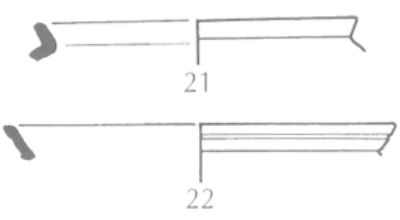

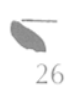

P1. 3. Les céramiques à parois fines de l'alelier de la Butle (échelle: 1/2). 

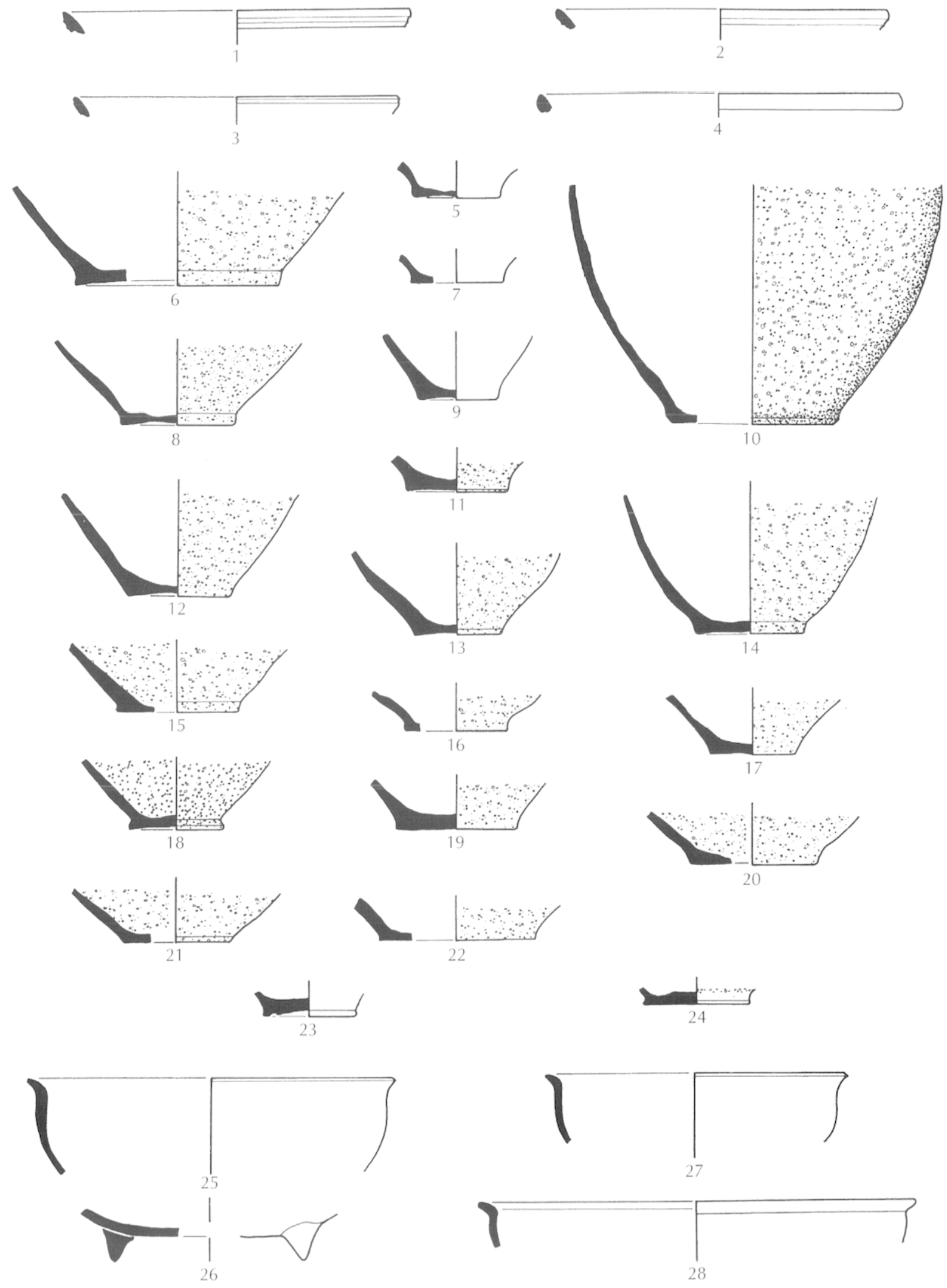

P1. 4. Les céramiques à parois fines de l'atelier de la Butle (échelle: 1/2). 

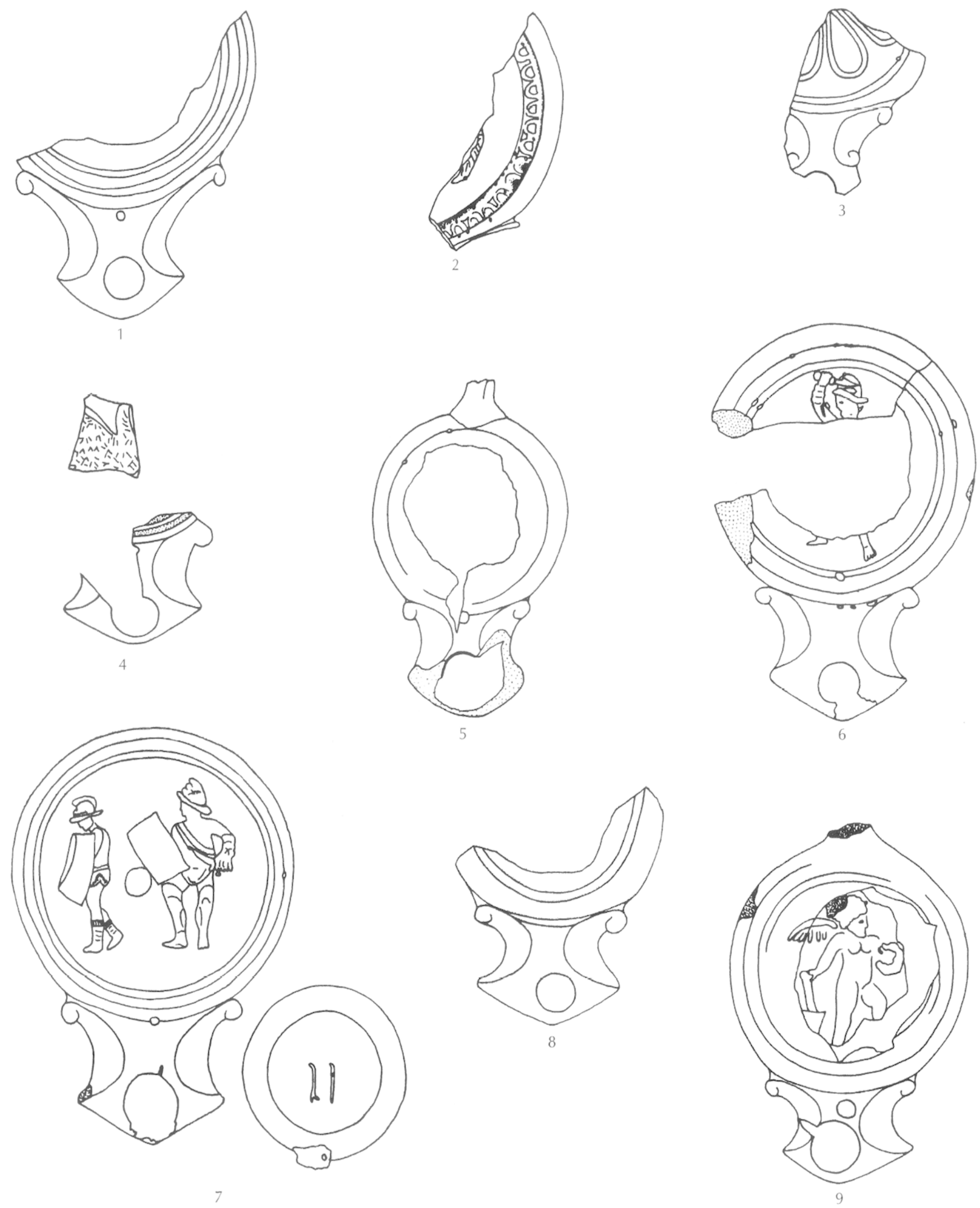

Pl. 5. Les lampes de l'atelier de la Butte (échelle: 2/3). 


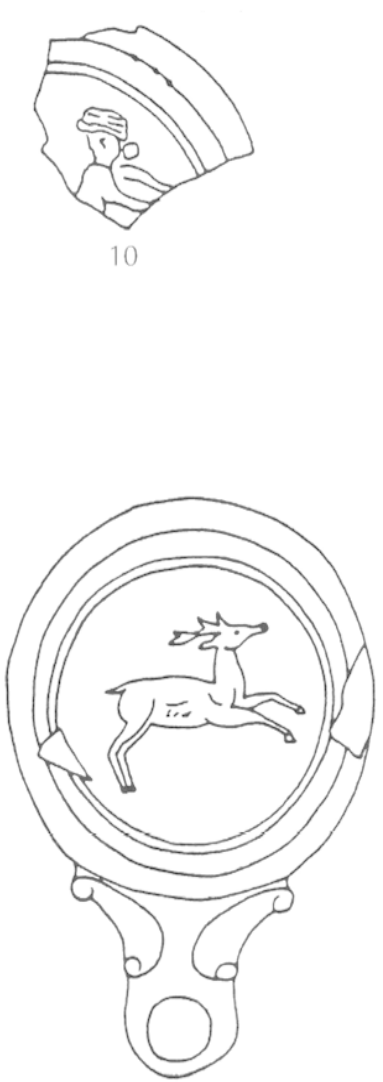

13

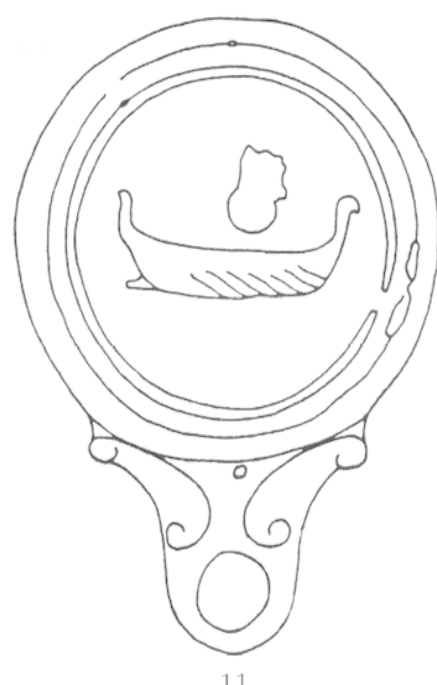

11
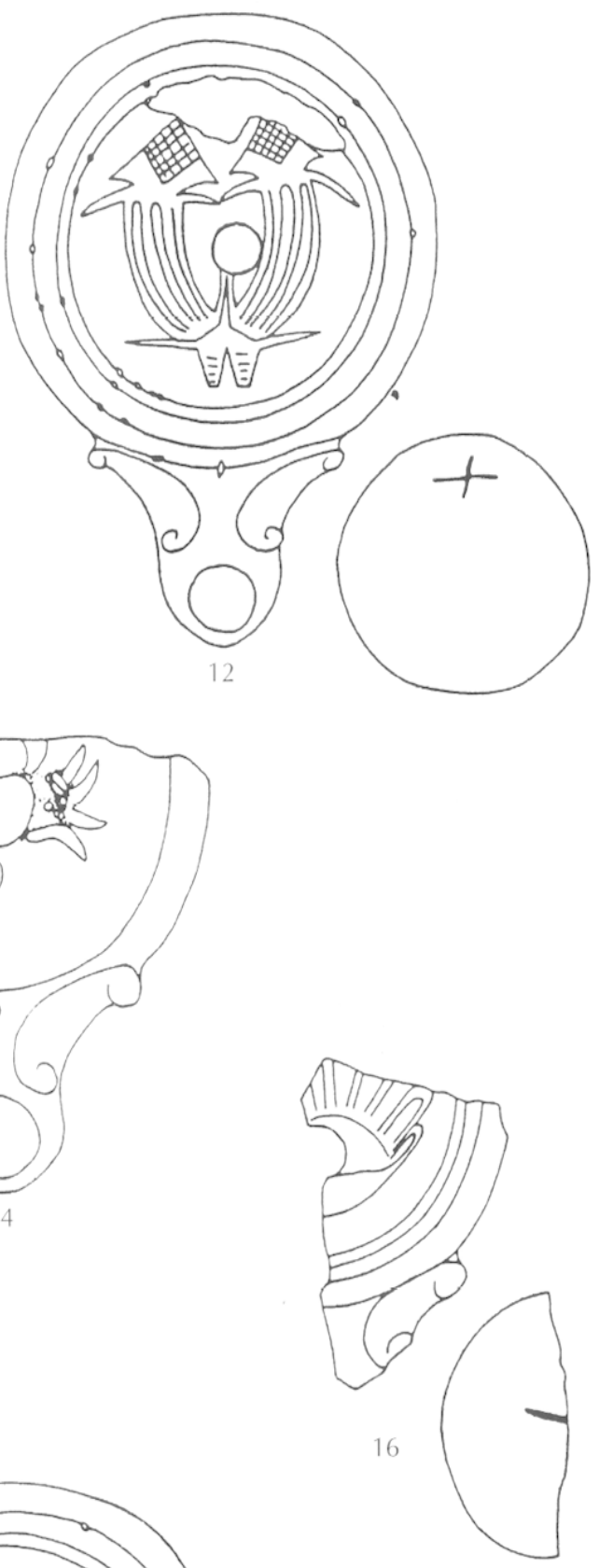

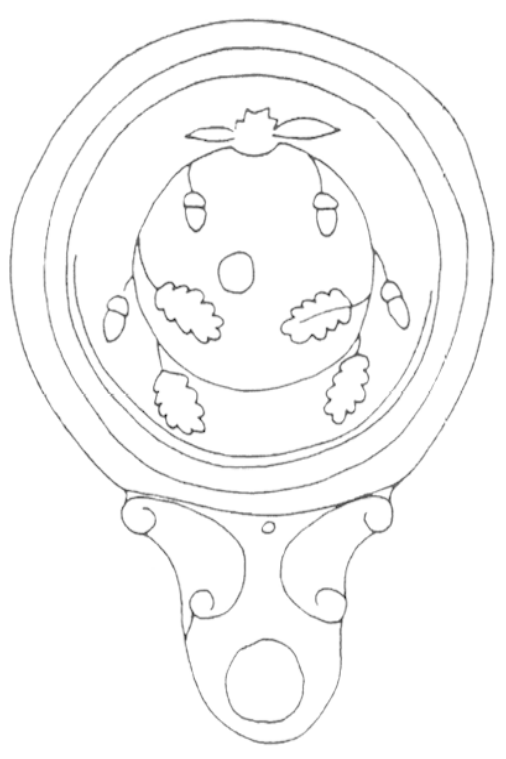

17
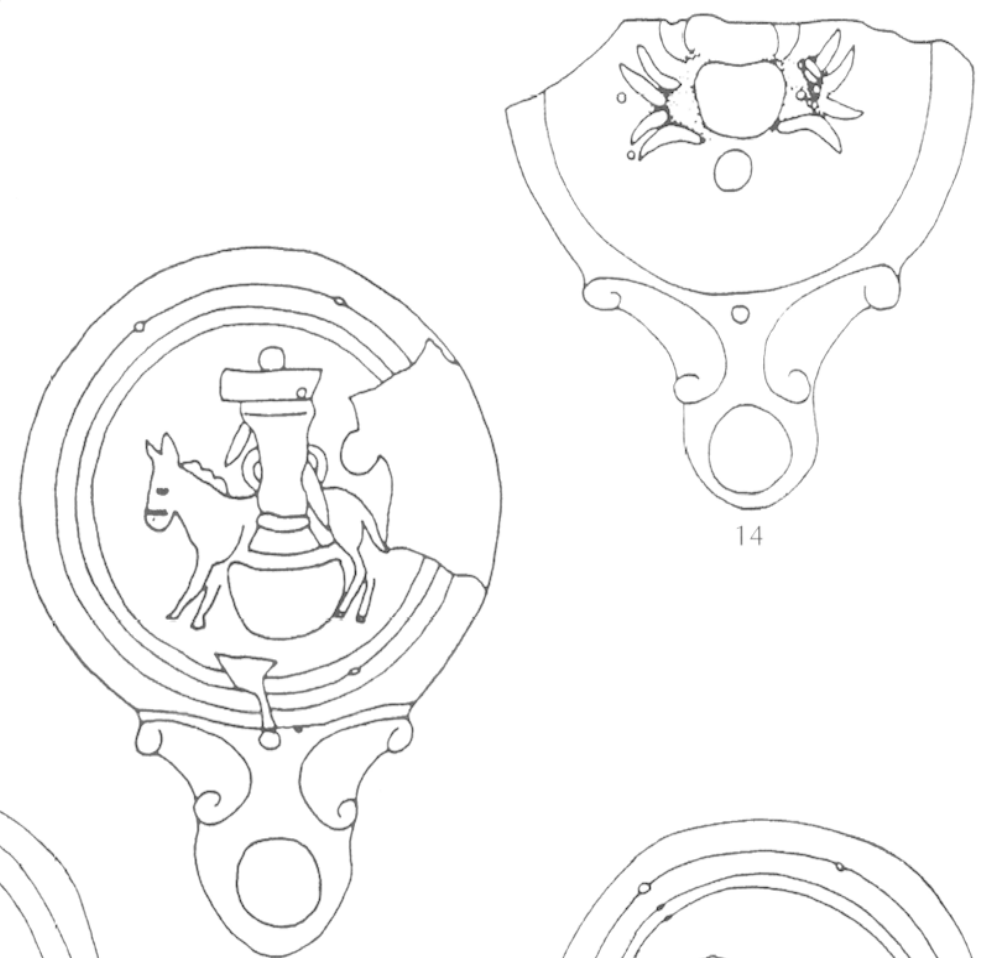

15

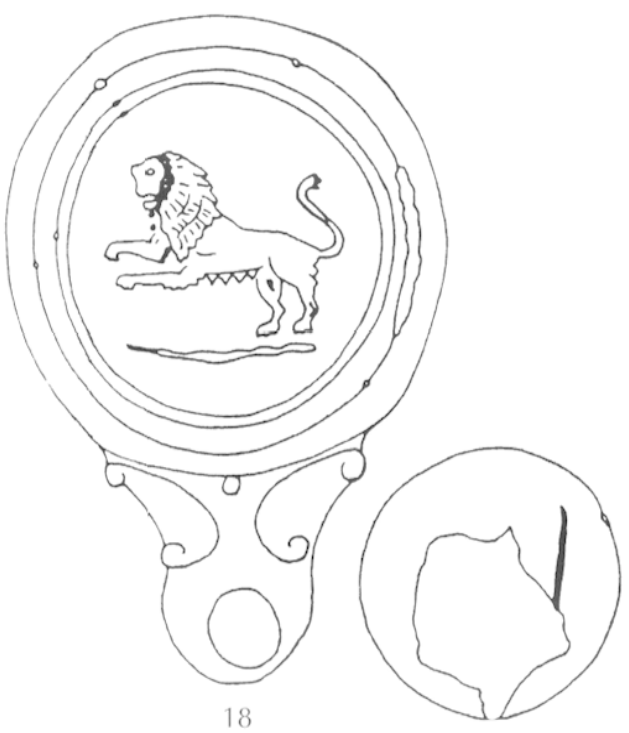

Pl. 6. Les lampes de latelier de la Bulle (échelle: 2/3). 

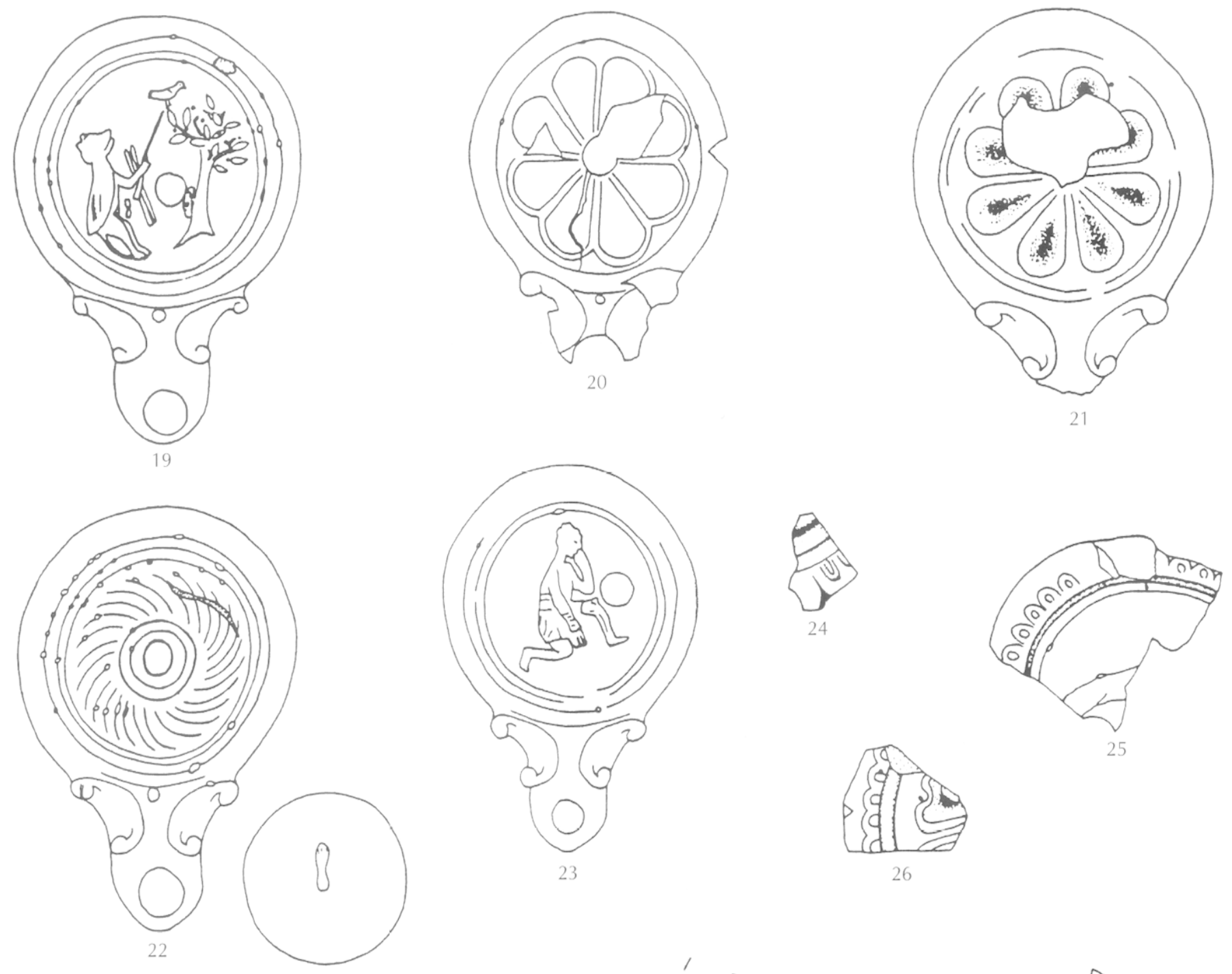

26
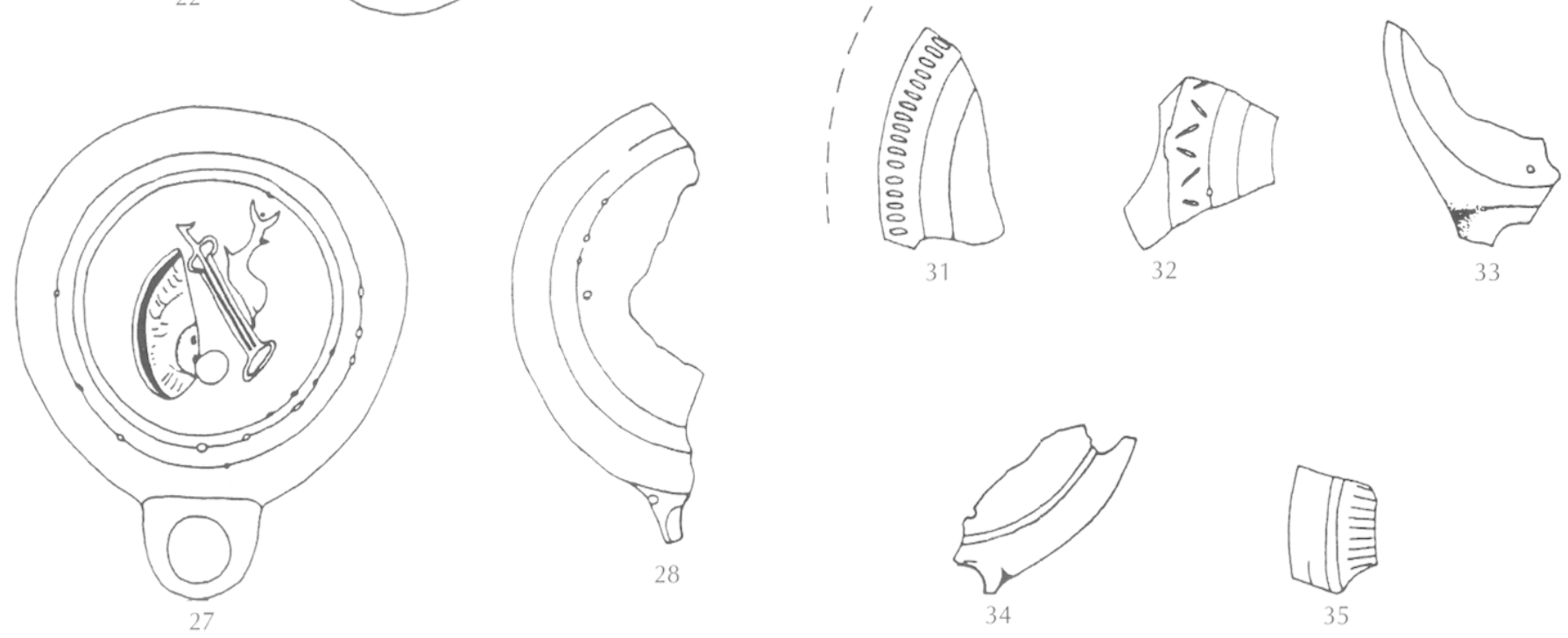

PI. 7. Les lampes de l'atelier de la Butte (échelle: 2/3). 

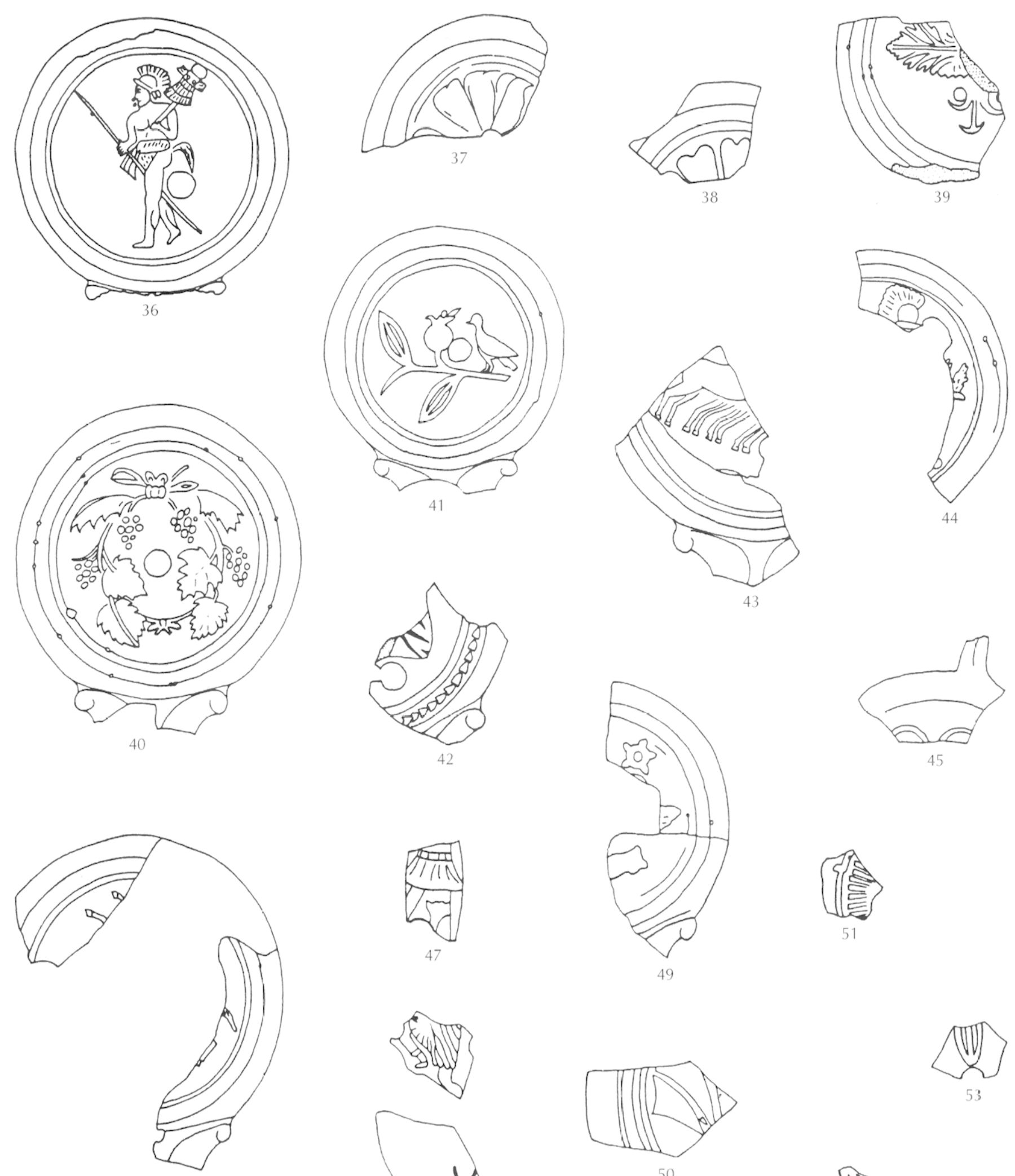

45

46
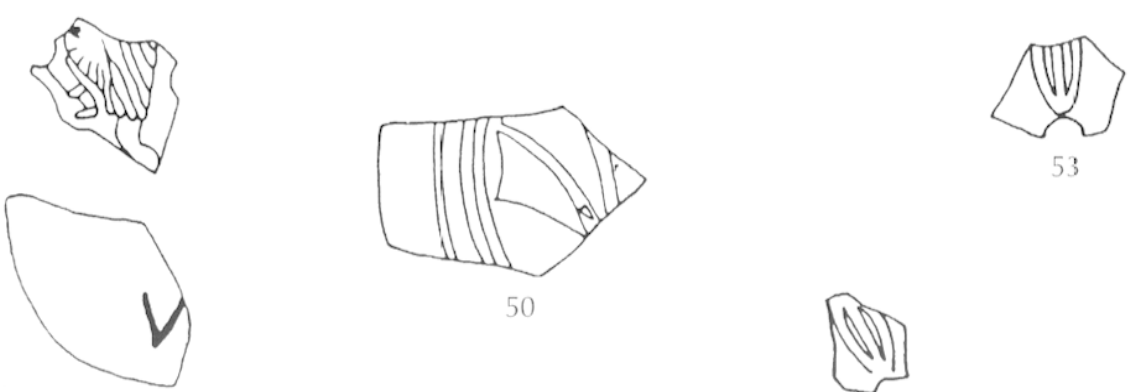

53
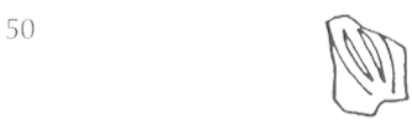

48

P1. 8. Les lampes de l'atelier de la Butte (échelle: 2/3). 


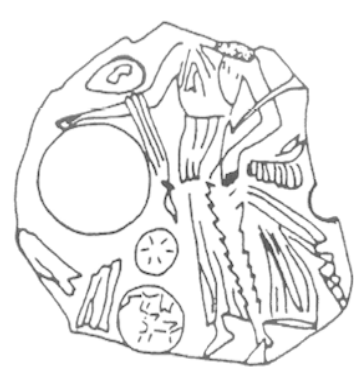

54

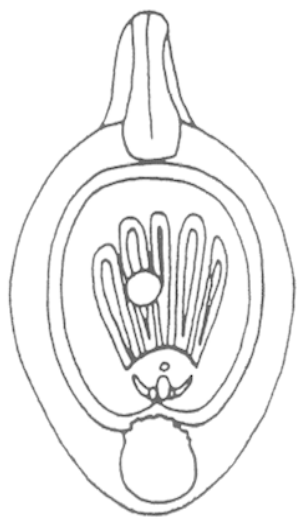

67
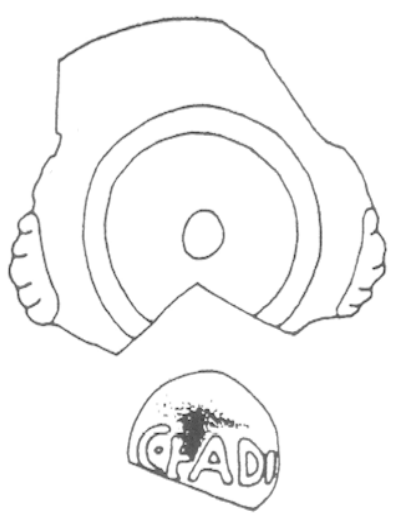

75
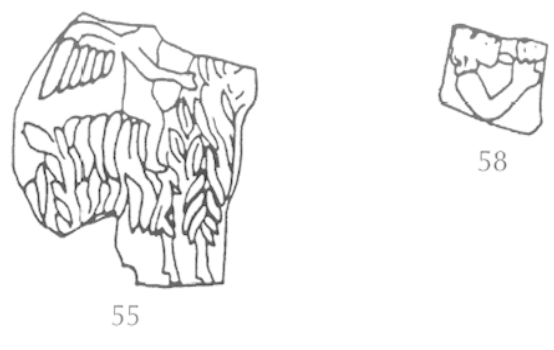

58

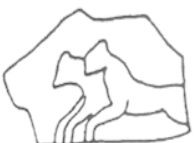

63
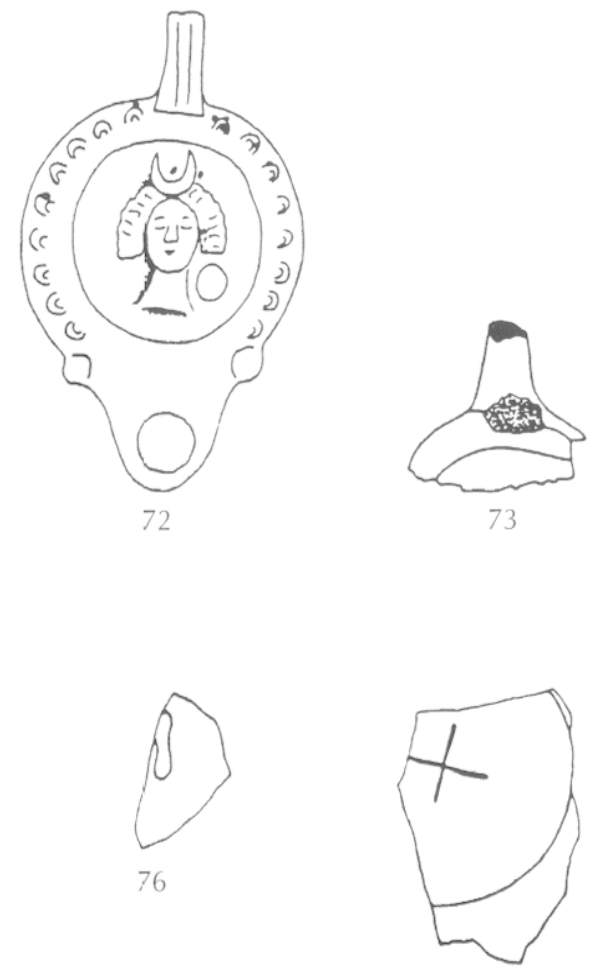

77

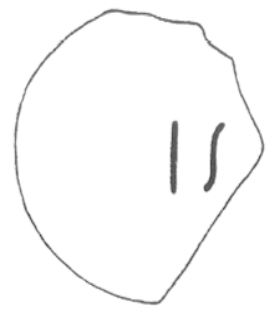

81

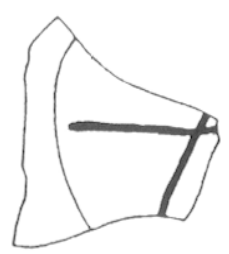

80
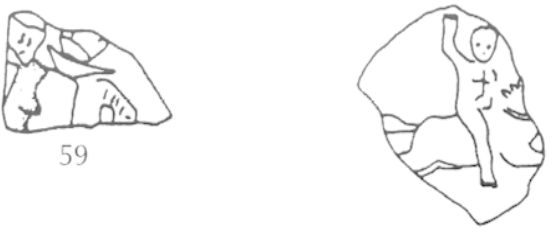

60

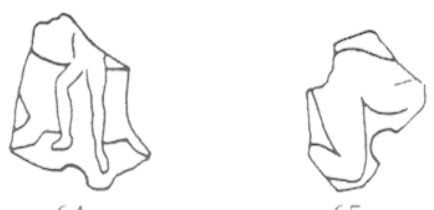

64

65

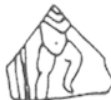

66
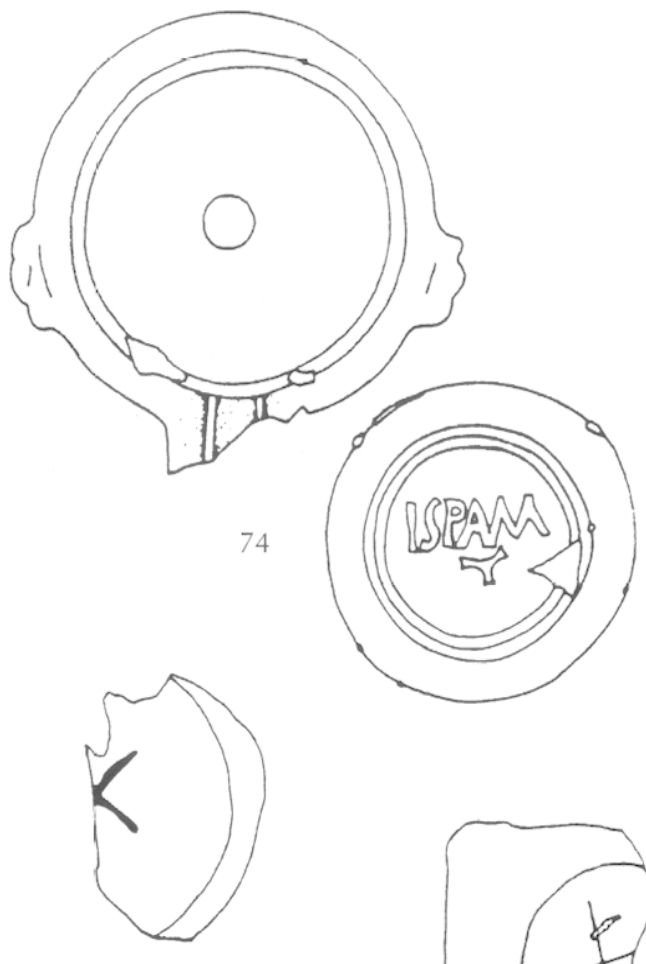

78
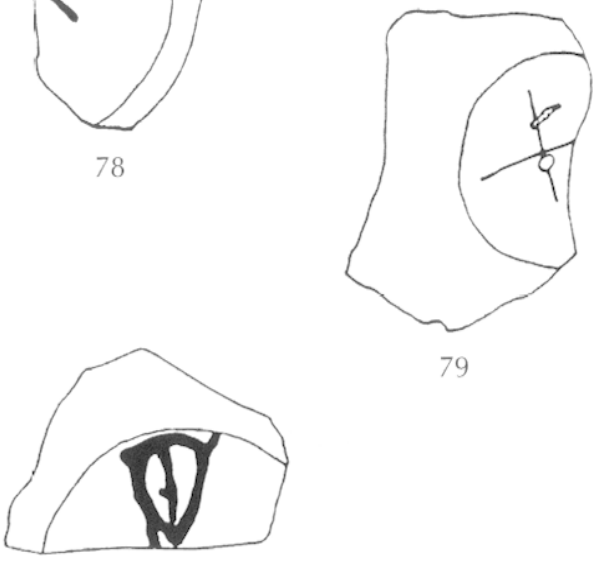

79

PI. 9. Les lampes de l'atelier de la Butte (échelle: 2/3). 

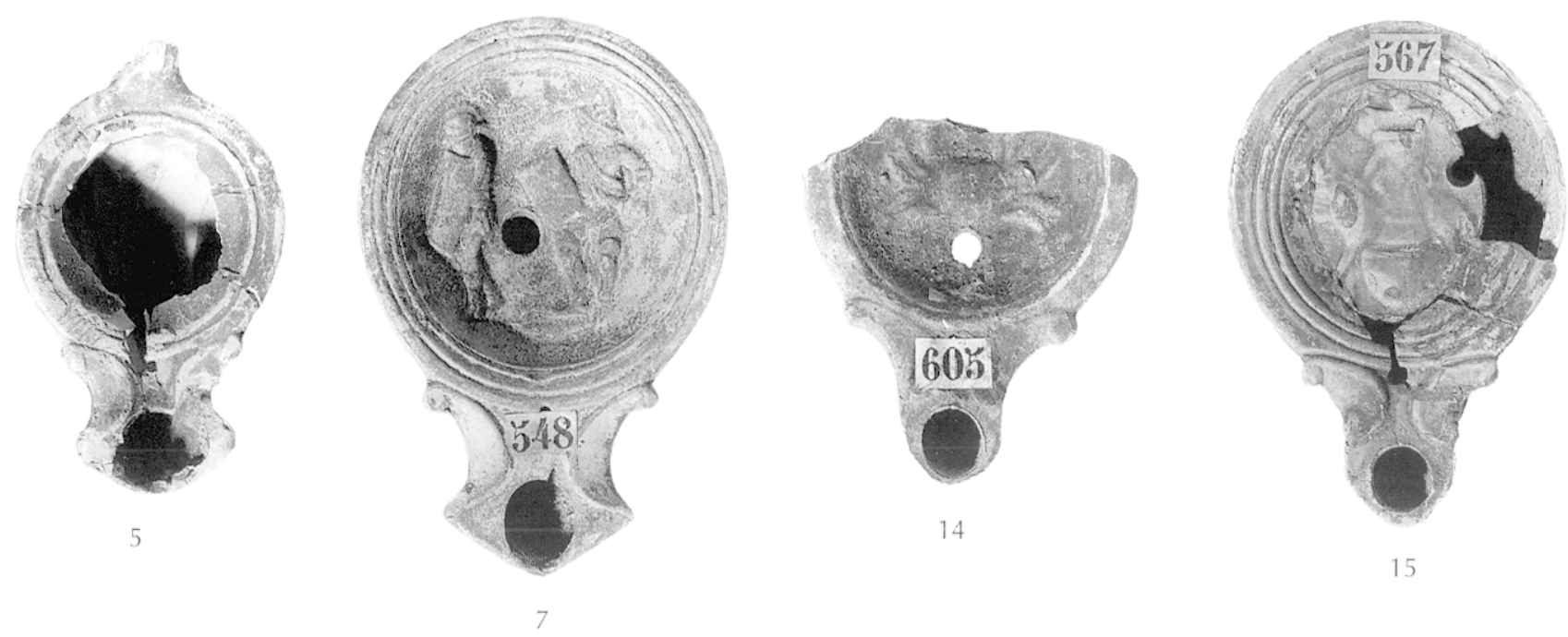

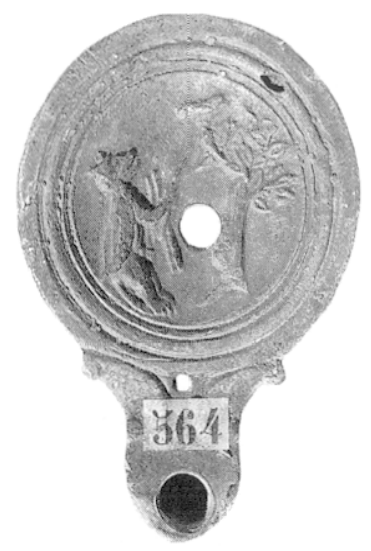

19

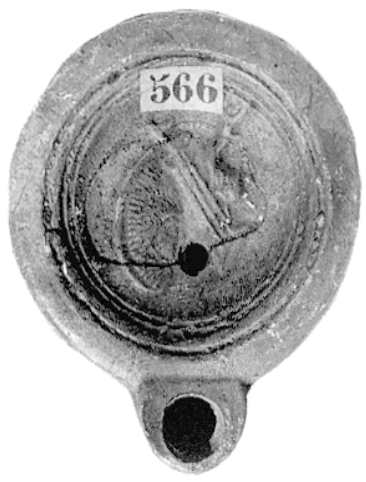

27

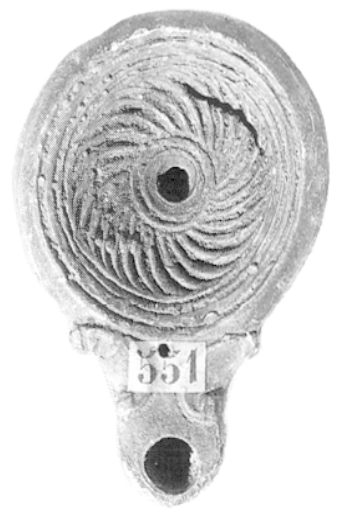

22

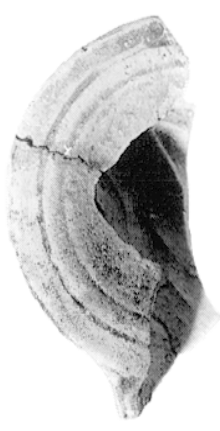

28

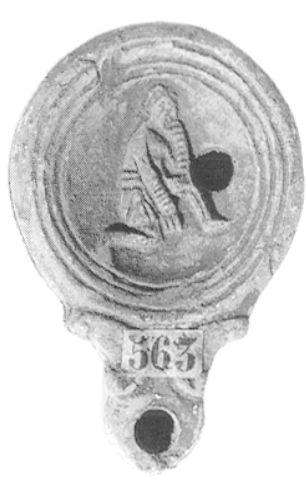

23

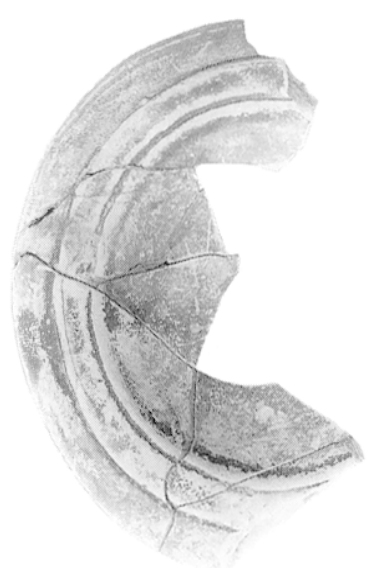

29

PI. 10. Les lampes de latelier de la Butte (échelle: I/2), (jhotos (: Thioc, MC(SRL). 


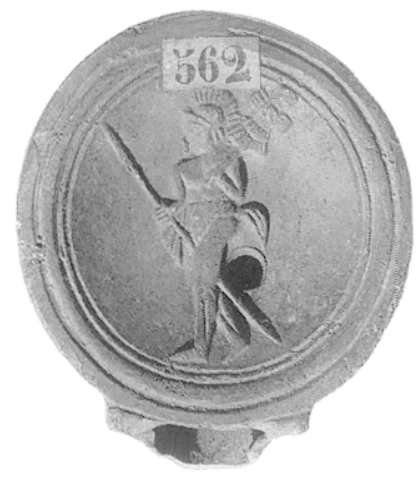

36

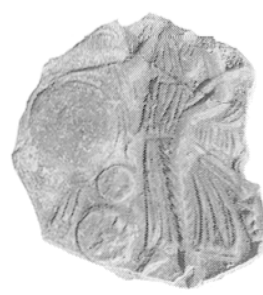

54

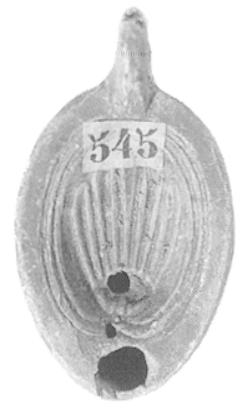

68

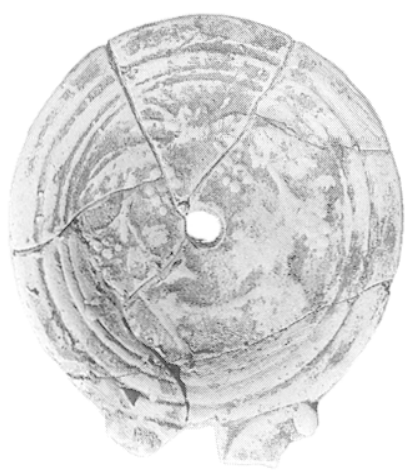

40

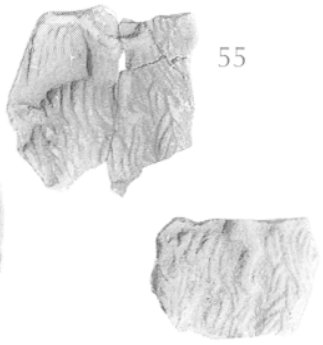

57
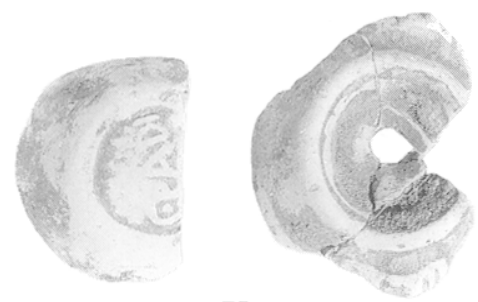

75

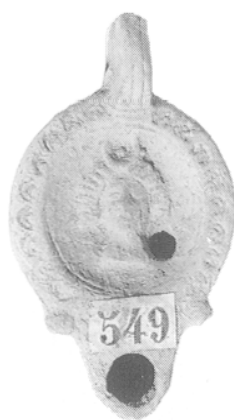

72

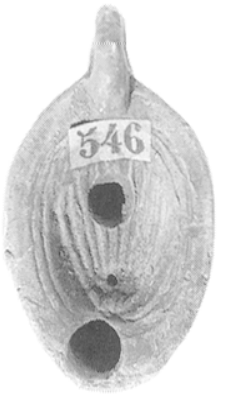

69

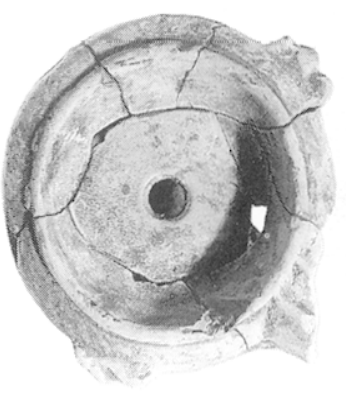

74

Pl. 11. Les lampes de l'atelier de la Butte (échelle: 1/2). 